This is the accepted version of the following article:

\title{
EVOLUTION OF RELIGIOUS CAPACITY IN THE GENUS HOMO: TRAIT COMPLEXITY IN ACTION THROUGH COMPASSION
}

by Margaret Boone Rappaport, Christopher J. Corbally,

in Zygon: Journal of Religion and Science, vol. 53, no. 1 (March 2018), pp. 198-239,

which has been published in final form at

https://authorservices.wiley.com/api/pdf/fullArticle/14861985.

This article may be used for non-commercial purposes in accordance with the Wiley SelfArchiving Policy [https://authorservices.wiley.com/author-resources/Journal-

Authors/licensing-open-access/open-access/self-archiving.html]

Abstract.

In this third and last article on the evolution of religious capacity, the authors focus on compassion, one of religious expression's common companions. They explore the various meanings of compassion, using Biblical and early related documents, and derive general cognitive components before an evolutionary analysis of compassion using their model. Then, in taking on neural reuse theory, they adapt a model from linguistics theory to understand how neural reuse could have operated to fix religious capacity in the human genome. They present a teaching tool on "Religious Capacity in Action," and develop an example of compassionate decision making in very early Homo sapiens in North Africa. They round out their analysis of compassion by exploring theory in neuroscience on a standard decision-making model, and investigate what goes on in the human brain when a values-based decision is made.

Keywords:

anthropology; cognitive science; compassion; cultural evolution; decision making; evolutionary biology; genetics; neural reuse; neuroscience

Margaret Boone Rappaport is an anthropologist, biologist, and co-founder of the Human Sentience Project, Tucson, AZ, USA; e-mail: msbrappaport@aol.com.

Christopher J. Corbally, SJ, is an astronomer with the Vatican Observatory and Department of Astronomy, University of Arizona, Tucson, AZ, USA and co-founder of the Human Sentience Project; e-mail: corbally@as.arizona.edu. 


\title{
EVOLUTION OF RELIGIOUS CAPACITY IN THE GENUS HOMO: TRAIT COMPLEXITY IN ACTION THROUGH COMPASSION
}

\author{
Margaret Boone Rappaport, Christopher J. Corbally
}

...it's odd that the greatest sympathy for evolutionism is found among scholars who study the distant past. For events of this century, and especially of the last few decades, suggest that the arrow of history identified by some social scientists of the nineteenth century is roughly on target. Lewis Morgan's essential point was right: the endless impetus of cultural evolution has pushed society through several thresholds over the past 20,000 years. And now it is pushing society through another one. A magnificent new social structure- our future home—is being built before our eyes.

Robert Wright (2001)

\section{INTRODUCTION}

This is the third in a series of three papers that describe the theoretical underpinnings of an evolutionary model for the biological emergence of religious capacity in the genus Homo. In the first paper, "Evolution of Religious Capacity in the Genus Homo: Origins and Building Blocks," (Rappaport and Corbally 2018a), important adaptations undergirding modern human religious capacity are identified, probed, and set in place for a model that is presented more fully in paper two, "Evolution of Religious Capacity in the Genus Homo: Cognitive Time Sequence" (Rappaport and Corbally 2018b). Paper two explores additional cognitive, neurological, and genomic research findings that support our model for the biological evolution of religious capacity, which, we propose, occurred only in Homo sapiens. The evidence for this contention is presented fully in papers one and two, but here in paper three (Rappaport and Corbally 2018c), important evidence is marshaled that involves the singular expansion of the precuneus in the brain of modern humans (Bruner and Iriki 2016; Bruner et al. 2017).

In papers one and two, we explored the importance of the evolution of plasticity on the human line in determining human intellect and, we propose, religious capacity. In paper two, we also delved into fossil, archaeological, genomic, and paleoneurological (Gunz et al. 2010) research findings on humans' nearest, extinct relative, Homo neanderthalensis. As a result, we rejected the notion that this species had theologically based religious thinking, and explain the evidence for our reasoning. We then focus on the timing and sequence of adaptations supporting religious capacity, and the response to different selection pressures. On the evolutionary line leading to our species, until the agricultural revolution 10,000 years ago, genetic drift could well have played an important role because populations were small—reduced from the large, genetically variable, Eurasian ancestral ape population of the Miocene, down to the reduced ape population 
that gave rise to the genera Homo (humans) and Pan (chimpanzees and bonobos) in Africa (Begun 2016; Harris 2015; Schrago 2013; 2014).

The evolutionary model we propose has some very practical uses. In this paper, we illustrate an analytical approach to the very complex human ability to form "compassion," which is often understood as a consequence of religious thinking. The same type of analysis could be used for other human abilities often connected to religious capacity, for example, empathy, charity, and forgiveness, each of which is cognitively (and linguistically) complex, as well.

While we identify six important evolutionary stages in paper two, here, we refine two of our "building blocks," so that our analysis more fully addresses traits developing in the ancestral ape population that gave rise to our genus, Homo, 2.8-3 million years ago, if the latest finds hold (Villmoare et al. 2015). The result is ten evolutionary stages, which often overlap each other in time, start and stop, begin again, and proceed in adaptive spurts that can sometimes be identified in "selective sweeps" in the human genome. The ten evolutionary stages that are fundamental to religious capacity's biological evolution are presented in Table 1, in an order that is often corroborated by the fossil record, but also in a logical order that underscores the challenges presented to preceding populations of evolving hominins, and how they were solved by new populations. We emphasize that 4 to 8 in Table 1 were all occurring in the same general evolutionary stage, around 8-10 million years ago.

Table 1. Major Evolutionary Stages for the Analysis of Human Characteristics Typically Related to Religious Thinking

1. Sociality in all Primates, emerging 55 - 65 million years ago

2. Basic ape model from the Miocene at around 19 million years ago (pegged to a fully ape-like Proconsul)

3. Realignment of the senses, upgrade of vision and hearing, bouts of adaptation for hominins

In at least some groups of the ancestral ape population giving rise to the genera Homo and Pan in Africa, changes 4. - 8 .

4. Down-regulation of aggression, around 8 - 10 million years ago, lengthening developmental trajectory, and secondary altriciality

5. Greater social tolerance among adults, especially while feeding

6. Upgrade in intellect to manage aggression

7. Greater sensitivity, general and emotional

8. Biological foundations for a capacity for culture

9. Moral capacity emerges possibly in Homo erectus, 1 million years ago

10. Religious capacity emerges in Homo sapiens, 300,000 - 400,000 years ago

We ask: Where, in all these evolutionary underpinnings of religious capacity, can we identify factors supporting the likely emergence of a culturally and cognitively complex feature like “compassion”? We note our use of the term "trait” for "religious capacity” (i.e., religious thinking) is the same sense used by biologists (Varki and Altheide 2005). The importance of the globular skull shape in defining the appearance of fully modern humans was introduced in papers 
one and two, where we focused on the significant expansion of the parietal lobes to achieve that geometric shape, particularly the expansion of a portion of the parietals called the "precuneus" (Bruner and Iriki 2016). The bulging of this region is "a feature unique to our species" and furthermore, “...the comparative neuroanatomical and paleontological evidence suggest that precuneus expansion is a neurological specialization of $H$. sapiens that evolved in the last 150,000 years that may be associated with recent human cognitive specializations” (Bruner et al. 2017, 1053; cf Bruner and Pearson 2013). We suggest later that the precuneus is singularly important in the emergence of theological thinking. We shall return to the parietal lobes of the brain in our evolutionary analysis of compassion and explore what, if anything, the expansion of the parietal lobes might signal about religious thinking. Did other functions of the parietals shape what we now identify as religious capacity?

Toward the end of this paper, we provide a teaching tool on "Religious Capacity in Action," which is an account of religious thinking in very early Homo sapiens in North Africa, at around 150,000 years ago. We have chosen early humans in that location as an example of changes that were occurring not just there, but in the species Homo sapiens continent-wide (Hublin et al. 2017; Callaway 2014). The recent finds at Jebel Irhoud, in present-day Morocco, show Homo sapiens with different degrees of a rounded, globe-shaped skull, and consequently, different levels of parietal expansion. Some of this same variability is seen in fossils from another site, Omo, in present-day Ethiopia, at about 200,000 years ago (Fleagle et al. 2008). The difference is that the recent finds go back over 300,000 years (Hublin 2017 et al.; Callaway 2014).

In our teaching tool, the neurologically enabled and culturally based action in our "Story of Bo" (an evolved descendant of the Bo appearing as a Homo erectus youth in Rappaport and Corbally 2017) frames phenotypic expression of the human trait of religious capacity, now and in the past. This teaching tool is presented as fiction because of two unavoidable facts: (1) We do not have time machines and cannot conduct field research among early humans, and (2) we conclude that compassion has a cognitive evolutionary history because it exists among modern humans, with historical examples stretching back into antiquity. Our story also illustrates compassionate thinking in action because, as we shall see, compassion is action-oriented.

\section{CULTURE, COMPASSION, AND WISDOM}

We propose that compassion is a sequence of cognitive steps that draws on a functional network of distributed neural structures, probably many of them "re-used" or "re-deployed" (Christiansen and Müller 2014) from earlier evolutionary purposes. Compassion includes several decisionmaking loops and eventually, planned behavior, which may or may not be actualized. There can be negative cultural feedback if action is not taken, but there can also be positive feedback if action is not taken, too, with a group consensus that the wiser course of action was "to do nothing.” Compassion is often blocked by countervailing cultural factors, as well as practical concerns about resource stores and social stability. Compassion can be quite costlyeconomically, emotionally, and in terms of energy expenditure-so we shall re-visit some of the mechanisms we identified in paper two that can cognitively cut compassion short. This termination has been interpreted by some researchers as energy efficient from an evolutionary perspective. Our view is that it might be efficient, but it remains a human choice. 
We suggest that curtailing compassion can be unlearned, using additional decision-making loops. Furthermore, we propose a higher-level type of evaluation of multiple compassion-driven actions, which considers broader results, as well as conflicting pragmatic factors, emerge as an estimation of relative wisdom. Not all compassionate thinking and action reaches this level, but when it does, the result can morph into something very different from compassion. It can feed into what is still parsed by philosophers as "wisdom.” Social scientists have lagged in research on wisdom.

Our model suggests that religious thinking and compassion became tightly interwoven by culture once fully modern Homo sapiens appeared, although they can still be viewed as separate even today, because compassion is not always driven by religious thinking, but by, for example, justice, equity, and fairness. We suggest that sociality (characteristic of the order Primates for 55-65 million years) was not enough to trigger compassion, primarily because forms of sensitivity and capacities for complex decision making were not yet available. They came later when our species evolved, although other forms of benevolent behavior surely existed amongst members of earlier species on the human line.

We may think we see compassion in other animals and the ways they behave toward us and other animals. Our view is that we read into non-human behavior what we are most familiar with, from being human, and call it compassion without realizing how very complex it is cognitively, especially if we are deriving compassion from a religious theology. Other animals have not had our long evolutionary history of a down-regulation in aggression, upgrades in sensitivity and intellect, and finally, the emergence of executive functions allowing us to see ourselves and others in counter-factual circumstances. Those abilities allow the perceptions, emotions, and sensitivities related to compassion to be traced out to their logical ends, in the future. With an ability to envision what might happen if we do, and do not, take compassionate action, humans care for others in ways that other animals cannot grasp. Their consciousness of their own and others' place in the world and in time, does not reach that level. Other animals behave toward one another in many caring ways, but not, we propose, as the result of compassion.

Eight to ten million years ago, before the hominin and chimpanzee lines emerged from a reduced ancestral African ape population, the biological foundations for cultural capacity flowered in some groups and were eventually instrumental in the emergence of compassionate thinking and behavior. After early Homo sapiens appeared, culture and compassion likely evolved together in one of the complex feedback loops that characterized the evolution of small groups of early humans, in which higher-level cognitive abilities became better fixed, in part as a result of their own supportive actions (Bruner and Iriki 2016, 103). The ability called "human compassion" must have emerged somewhat later than culture, not necessarily because the perceptual, sensitivity, and emotional basis for compassion lagged, but probably because decision-making faculties were not yet quite fixed, both neurologically and culturally. Decision making may have been refined subsequent to genetic drift in small groups of hominins, or because it was so advantageous from a perspective of natural selection, or both. Drift and natural selection can work together (Matute 2013). Irrespective of how they became part of our genome, the biological foundations for complex decision making rendered early humans more adaptively fit, allowing them to survive and reproduce. They do the same for us today. 
Culture came to explain and rationalize the perceptions, emotions, sensitivities, and decisionmaking loops of compassion, in different ways, in different cultures, where it most often appears as a companion to religious theology, and when implemented, as behavior reflecting religious beliefs and commitments. Cultural evolution also enabled the process responsible for the fixation of some of the cognitive components of both religious capacity and compassion, through generation after generation of testing the best courses for both thinking and action. This is not to say compassion has no foundation in the evolution of primate biology. It does, and we shall explore some of the ways that it does. It is simply that, through neural reuse, culture played a role in fixing certain traits, by accommodating religious thinking to existing brain structures, not the other way around, in a manner parallel to language (Christiansen and Müller 2014).

What remains uncertain is whether our species is the only member of the genus Homo to exhibit compassion. Was compassion a capability solely of Homo sapiens, or did the extinct, closely related species Homo neanderthalensis, likely have cognitive features consistent with compassion? Did Homo erectus? We concluded at the end of paper two that Homo erectus likely had some forms of ritual, but cautioned that ritual does not equal religious thinking. We also concluded that it was unlikely that the Neanderthals had theologically-based religious capacity because of the absence of the same expansion in the parietal lobes that we see in Homo sapiens. If Neanderthals did not have religious capacity, could they have had compassion? That remains an open question, and raises issues about the relationships between compassion, religious thinking, and parietal lobe expansion, which we address, in part, toward the end of this paper.

To help us decide which cognitive components we should examine in our analysis of compassion - the reader should note that there have been many and widely varying definitions of it - we return to a historical period of time that is much more recent than the evolutionary and archaeological time periods we have used to this point. We shall examine a source of understanding - the Bible and related documents - to see how our current concept of compassion became bound to religion in the modern world. The history of words can often reveal how a vocabulary emerged, why a lexicon changed, and the social forces behind the use of words in certain ways. Our examination of the emergence of "compassion" in western thinking can only go back a little over 2,000 years. The early Homo sapiens family depicted at the end of this paper lived 150,000 years ago! David, Jesus and other principals in the Bible lived $1 / 75,000^{\text {th }}$ of that time ago, so it is important to understand that we focus on a time period that is, comparatively, "just yesterday." Nevertheless, in comprehending the Greek and Hebrew words for compassion, we come to see some of its essential nature, and therefore, the cognitive components of compassion that we should identify before we look back into the evolutionary record of the human line, to understand where it came from, and why.

\section{A SEARCH FOR THE COGNITIVE COMPONENTS OF COMPASSION IN RECENT JUDEO-CHRISTIAN AND GREEK TEXTS}

Our goal now is to identify compassion's essential cognitive components. While the neurological and genomic underpinnings of these components (and therefore compassion) are still largely unknown, it appears to us from our research on religious capacity that a few are known. They signal the type of biological foundations we hope will someday be more fully identified and understood. 
The advantage of this etymological analysis will not only be a deeper understanding of a singular cognitive trait of our species, but it may point toward steps to teach compassion to humans who appear compassionless. They do exist, and by themselves, they suggest a genomic substrate for this human ability and its usefulness. Humans can live without an ability to form compassion, but not many of them do, even if some might lead lives that to us seem reprehensible. Compassion is found too often in deeply probing interviews, as well as historical texts. This suggests a widespread distribution for a cognitive trait found useful in generation after generation of humans. Logically, if compassion had not been found beneficial, its absence would not be so rare or, so clear to us when we encounter it-or fail to.

We shall search for the term "compassion" and trace its origins in Hebrew (the language of the Old Testament) and Greek (the language of the New Testament). We also examine Greek translations of originally Hebrew biblical texts and related documents. The results were interesting, especially when we combined the viewpoints from our separate training in theology and anthropology. Religious capacity (our initial interest) appears to be firmly linked to compassion in meanings that have dominated western thought for well over two thousand years. Religion may be content with calling compassion a divine revelation, but an anthropologist is aware of the biology underneath, and so is the thoughtful astronomer-priest.

The term “compassion” has a history like many English words. Compassion can be traced from modern English, to Middle English via Old French, from the Latin noun, compassio, from the verb compati, which means "to suffer with.” Existing definitions of the English word compassion suggest it means "to suffer together." To students of emotion, it is often defined as a feeling that arises when one is confronted with another's suffering and one experiences a motivation to relieve it. Therefore, it has at minimum two cognitive steps: some type of perception, and some wellspring of motivation.

However, in examining basic definitions over the past two thousand years, we already see a multi-step process, as well as the potential for a religious explanation for some very strong emotions (whose origins may pre-date the hominin line), but whose interpretations, with help of the human prefrontal cortex, may be more recent. We glimpse the emergence of a religious rationale for some types of social activities that help—someone-who? That varies crossculturally and intra-culturally according to sometimes conflicting norms and values. We can already envision the decision loops involved in compassion, and we see that they are culturally influenced. Compassion is not an instinct or a reflex. It has origins in perceptions and special sensitivities, but when they occur, their explanation and disposition are largely cultural.

Table 2 is a list of Greek words for "compassion" and its derivatives that began with a search of the NASB Greek-English Interlinear of the New Testament (Olive Tree). In terms of usage in the Bible, we note recent changes of the words, "moved with compassion" in the English Standard Version (ESV) of the Bible, to "moved with pity" in the New Revised Standard Version (NRSV). The words associated with "compassion” continue to vary, so it will be useful to begin with words used closer to the origination of the books of the Bible and its associated texts. 
Table 2. Greek Terms for Compassion, and Derivatives

\begin{tabular}{|c|c|c|}
\hline 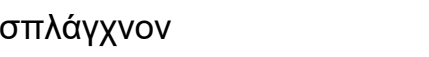 & splágchnon & compassion \\
\hline 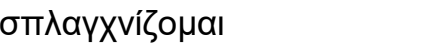 & splagchnízomai & to have compassion \\
\hline 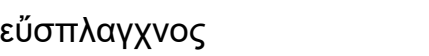 & eúsplagchnos & tender-hearted \\
\hline 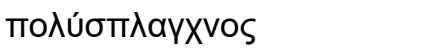 & polýsplagchnos & compassionate \\
\hline 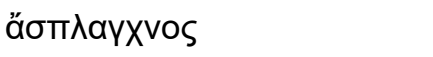 & ásplagchnos & without mercy, merciless \\
\hline \multicolumn{3}{|c|}{ From the Enhanced Strong's Dictionary of the Bible ${ }^{* *}$} \\
\hline 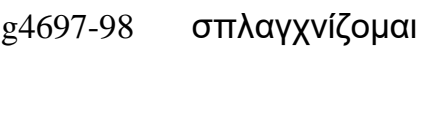 & splagchnizomai & $\begin{array}{l}\text { to have the bowels yearn, i.e., } \\
\text { (figuratively) to feel sympathy, to pity, } \\
\text { to have (be moved with) compassion }\end{array}$ \\
\hline 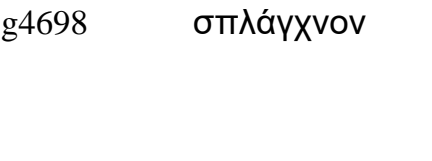 & splagchnon & $\begin{array}{l}\text { probably strengthened from } \sigma \pi \lambda \eta \dot{ } v \\
\text { splēn (the "spleen”); an intestine (plural); } \\
\text { figuratively, pity or sympathy: bowels, } \\
\text { inward affection, + tender mercy. }\end{array}$ \\
\hline
\end{tabular}

* Kittel et al. 1985, with the more accurate, if awkward romanization of the Enhanced Strong's Dictionary.

** Enhanced Strong's Dictionary, Olive Tree Bible Software.

Early Greek usage is patently more literal than later meanings seen in Greek translations of the Hebrew biblical texts. This is not uncommon. Frequently, abstract words derive from more literal words for objects and often biological processes, either in the same language, older languages, or languages that were used by scholars (and so were widespread). For example, the Latin noun compassio, or Greek $\sigma \pi \lambda \dot{\alpha} \gamma \chi v$ vov [splágchnon, with the more accurate, if awkward romanization], was used mainly in the plural. The noun refers to the "inward parts" of a sacrifice, and then "the sacrifice," itself, and then the "inward parts" of the body, and finally, the "womb" or "loins," and in a derived sense, "children." The usage was extended to denote "impulsive passions" (anger, desire), and then "the seat of feelings or sensibilities." The Greek verb means "to eat the inner parts" (of an offering) or "to use entrails in divination." The term ásplagchnos means unmerciful, merciless, or cowardly ("with no guts"), and eusplagchnía denotes "boldness," thrasýsplagchnos means "fearless," and kakósplagchnos is for "spiritless" (based largely on Kittel et al. 1985).

We see clearly that the Greek root for "compassion” was originally quite literally visceral, but also had implications for the human spirit, will, and nerve. We note also that this root was originally associated with a religious ritual, i.e., sacrifice, so it is not surprising that it continued to be associated with religious thinking. However, readers should note the pre-Christian Greek term does not denote either pity or compassion. 
Somewhat later Jewish writings were often translated into Greek. For example, the Septuagint, or LXX, was a translation completed early in the Christian era. It is the primary Greek translation of the Old Testament. In this text, the noun and verb forms of the Greek word splágchnon are rare and seldom have Hebrew equivalents. The verb is used in the sacrificial sense in 2 Maccabees 6:8. The plural noun means "seat of feelings" in 2 Maccabees 9:5-6 (cf Proverbs 26:22; Sirach 30:7). The LXX uses the middle of the Greek verb in "to be merciful" (Proverbs 17:5), while the noun denotes "natural feelings" in 4 Maccabees 14:13 (Kittel et al. 1985).

The Testaments of the Twelve Patriarchs are examples of apocalyptic literature associated with the Bible. They are supposedly composed of the dying commands of the twelve sons of Jacob. The Greek splágchna occurs in these writings as "the center of feelings" or as "noble feelings." By extension, splágchna eléous is used for "loving mercy" in the Testament of Zebulun 7.3. In one instance, the verb signifies emotion but usually it refers to the inner disposition that leads to mercy. The Greek words eúsplagchnos and eusplagchnía stand for human virtue and disposition of "pity" in the Testament of Simeon 4.4 and the Testament of Benjamin 4.1 (Kittel et al. 1985).

The initially crude term splagchnía was eventually applied to God, himself, as in the Testament of Zebulun 8.2. It characterizes a divine nature relative to God's acts at the end of times, in the Testament of Zebulun 9.7. In the Testaments of the Twelve Patriarchs, splágchna, splagchnízomai, and eúsplagchnos replace the LXX’s oiktirmoí, oiktírō, and oiktírmōn, and offer new interpretations for the Hebrew texts (Kittel et al. 1985).

We see that in most of these Jewish writings, the meanings are clearly becoming less literal, and more consistent with human emotions and motivations, as well as God's. However, this is not universally true.

In general, these Greek translations of Hebrew texts dating after the Old Testament suggest that compassion involves deeply seated, internal feelings (including pity) and also the external disposition of the feelings. There is an inconsistent connection with the "noble" or "divine," but in these references, there remains an implied special quality. We would characterize the range of feelings as strong, emanating from deep within a person, and that their disposition is benevolent (merciful). It is noteworthy that Hebrew does not include early equivalents of the Greek concepts. Furthermore, we are not surprised that a word for deeply seated feelings that were then directed outwards would become attached to religious thought in the Christian church. Whether religion found an alignment with benevolent feelings and actions, according to the teachings of Jesus, to be useful, or whether leaders of the church thought the feelings of early members needed definition and direction, the human ability to form compassion seems to have found a good and early partner in religious capacity. While they are most often paired in practice to this day, they are not universally so. We see them as separable, with some overlapping cognitive origins and some that are different. We are becoming ever more convinced that the cognitive aspects of religious thinking, broadly speaking, are much more complex than for compassion.

In the Synoptic Gospels (Matthew, Mark, and Luke) under the original Greek versions of the New Testament, we see the word splagchnízomai (to have compassion). This verb occurs in the New Testament only in the Synoptics. In three parables, it denotes human attitudes: In Matthew 18:27, the Lord has pity on a servant; in Luke 15:20, a father has compassion for his prodigal 
son; and in Luke 10:33, the Samaritan has compassion for a man who has fallen among thieves. A Christian interpretation of these instances would be that they reflect the totality of God's divine mercy, to which human compassion is a proper response. Elsewhere in the Synoptics, the verb has messianic meaning, for it is only Jesus who shows compassion (Mark 1:42; 6:34; 8:2; 9:22; and Matthew 14:14; 20:34). In each case, what we appear to have is not so much the description of a human emotion as a messianic characteristic ( $c f$ Luke 7:13). (Kittel et al. 1985).

In the New Testament, pity and mercy become an aspect of Jesus' divine compassion. To us, it appears that the concept of compassion is emerging as having a divine quality or divine inspiration. An originally Greek term has morphed into a Christian revelation.

In Luke 10:33, the Parable of the Good Samaritan, the NASB Greek-English Interlinear defines the Greek word for compassion as, "to have the bowels yearn," that is, figuratively, to feel sympathy or to pity. The bowels were thought to be the seat of both love and pity for the Greeks of ancient times. The bowels were also regarded as the seat of the more violent passions, such as anger and love. However, the Hebrews regarded the bowels as the seat of tenderer affections, especially kindness and benevolence (Enhanced Strong's Dictionary; Harper 2017). For example, Psalm 25:6 of the King James Version reads, "Remember, O Lord, thy tender mercies and thy loving kindnesses; for they have been ever of old.” In this way, “compassion” means a heart in which mercy resides.

Paul's writings are also found in the New Testament, where he uses splágchna (the noun) not merely to express natural emotions but as a very forceful term to signify an expression of the total personality at the deepest level. The word splágchna is introduced in very personal passages regarding Titus' deep love for the Corinthians, and so it is parallel to kardía in 2 Corinthians 6:11-12, and to pneúma in 2 Corinthians 7:13ff. The Epistle to Philemon was written by Paul to the slave-master Philemon concerning a runaway slave called Onesimus. Twice in Philemon (vv. $7,20)$, Paul refers to the "refreshing” of the splágchna. In v. 12, he writes that Onesimus is coming in person with a claim for Philemon's love. In Philemon 2:1 splágchna kaí oiktirmoí seems to be summing up Paul's ideas about how he, and by extension Philemon should feel. In context, then, splágchna denotes Christian affection and oiktirmoí, Christian sympathy. Both are essential elements in all Christian interactions.

Apart from Acts 1:18 (“entrails”), the remainder of the New Testament usage develops under the influence of Paul or later Judaism. Colossians 3:12 refers to a Christian virtue; Luke 1:78 has in mind God's mercy at the end of times; James 5:11 also appears in an eschatological context. In 1 John 3:17, believers are not to close their hearts (the center of compassionate action) to the needy. There is hortatory use of eúsplagchnos in Ephesians 4:32 and 1 Peter 3:8. The terms splágchna and eusplagchnía are divine predicates in Acts of Thomas and Acts of John. This messianic use recurs, but in the latter, the apostle has pity in the same way as Jesus in a usage that differs markedly from that of the New Testament. (Kittel et al. 1985).

In writings by the Apostolic Fathers and other early Christians, Ignatius, when he writes to the Philippians (10.1) is the only one who reflects Paul's use of splágchna. In the First Epistle of Clement to the Corinthians (1 Clement 2.1), splágchna denotes the seat of religious conviction. 
God's mercy in salvation at the end of times is the point in 2 Clement 1.7, and divine compassion is referenced in 1 Clement 23.1.

We are beginning to see in the New Testament, as well as in early Christian writings that, the meanings of splágchna or compassion have gradually changed so that compassion comes to be understood a virtue related to religious capacity. Let us look further into the writings of the early Christian Church, and see how the usage evolves.

To bring our survey of definitions up to date, we list in Table 2 two definitions of compassion from the Enhanced Strong's Dictionary, for the New Revised Standard Version. Compassion, in the Bible, is a divine as well as a human quality. In the Revised Standard Version, the word is often used to translate the Hebrew hāamal and rahamîm, which are, however, in the King James Version, more frequently rendered as "pity” or "spare,” and "mercy” or “tender mercies," respectively. In this way, compassion, pity, and mercy could be regarded as synonyms.

The New Bible Dictionary states that prophets and other men of God were deeply aware of the wonder of God's mercy to sinful humans. They taught that anyone who had experienced this mercy would feel it his duty to have compassion on his fellows, especially "the fatherless, the widow, and the foreigner" (frequently named together as in Deuteronomy 10:18; 14:29; 16:11; 24:19; Jeremiah 22:3, and others), as well as those "in poverty and the afflicted" (Psalms 146:9; Job 6:14; Proverbs 19:17; Zechariah 7:9-10; Micah 6:8). There is no doubt from the frequent references in Deuteronomy that God expected his people to show compassion not only to each other but to foreigners who lived among them (Wood et al. 1996). In the teachings of Jesus, especially in the parable of the good Samaritan (Luke 10), it is clear that compassion is to be shown by his disciples to anyone who needs their help. It is desirable to be like Jesus, as expressed in one's deeds (1 John 3:17), and they may involve personal sacrifice. (Meiklejohn, in Wood et al. 1996).

In summary, we see that an originally Greek word changed in the way it was used throughout the Old and New Testaments of the Bible, and in texts related to the Bible. In being initially associated with a religious ritual (sacrifice of an animal to propitiate God or gods), it changes from a literal referral and becomes a more abstract virtue associated, in the end, with the divine. The type of religious connection changes, but the association with strong inner feelings does not change, nor does use of the word compassion, in referring to how the feelings are to be disposed. Eventually, compassion is associated with the teachings of Jesus, and illustrated in stories mainly in the New Testament that give guidance on how people should behave toward each other. The translations of "mercy" and "tender mercies," however, continue to lend a softer quality to a strong human sentiment, as well as an implication of softness and tenderness in the way others are treated, even (or especially) strangers or people without family or local support.

The concept of compassion, itself, like poetry, helps to solve a fundamental ambiguity in human experience: How to be strong, and how to be soft, when to be aggressive, and when to be tolerant. We shall explore some of the evolutionary roots of that conundrum. They are very old indeed, going back to the ancient ape population from which the genus Homo and the genus Pan emerged, 8-10 million years ago. An evolutionary perspective suggests that compassion is one way to solve the aggression-tolerance bind, about which we shall have more to say, below. Some of the psychology literature understands compassion as a rational capacity and one that entails 
“judgment” (Deane-Drummond 2017; Nussbaum 2014), and we agree with both generalizations. This differs from other segments of the psychology literature in defining compassion primarily as an emotion, and as a desirable characteristic in a mate (Goetz et al. 2010). We suggest that both latter views minimize the complexity of human compassion, in essence and in function.

In contrast, our view is that compassion derives first, from ancient upgrades in the sense of vision and hearing, and upgrades in social sensitivity deriving from a down-grade in aggression among our ape ancestors. Eventually, after cultural capacity emerges, compassionate action derives from core cultural precepts on what is real and not real, right and wrong, desirable and undesirable, and its disposition relies fundamentally on advanced decision-making skills that arose only in Homo sapiens. Through compassion and other human action-oriented abilities, religious capacity is reworked neurologically by cultural neural reuse, and comes to co-op some neural substrates and new neural circuitry cross-culturally. That accounts for its similarities from group to group ( $c f$ Christiansen and Müller 2014).

The emotions attending compassion, while deriving from the "center" of a human being (as we noted from our etymological analysis), can be expressed in a variety of ways that are culturally appropriate. Some cultures call for quiet embarrassment at strong emotions and convictions. Other cultures call for their full demonstration. Therefore, we propose that the types and strength of emotions have less to say about the nature of compassion than the decision making that attends it. Indeed, compassionate action can be followed with little emotion at all, except for a deeply felt conviction that some action (or no action) is the "right" thing to do. Compassion reflects core values more than it reflects variable personal feelings.

The changes we describe-evolutionary, biblical, and cultural-are not without contemporary importance. The ability to form compassion and direct it outward toward others, even strangers, is a universalization of benevolence that before was almost always confined to family and the home. Now, from our analysis of compassion in the Bible and related documents, we see that compassion and its resulting actions are supposed to be directed to unknown others and by extension, to everyone. Some types of genetically based human sensitivities go along with this, but not all, as we noted in paper two. In many of cultural anthropology's evolutionary accounts over the years, we find that religion, little by little, comes to stand for increasingly universalistic values, virtues, and even social goals ( $c f$ Harris 2001; Peacock and Kirsch 1970). We see these trends emerging and strengthening with the growth of nation-states where many different people interact in complex ways, and even more so now, with the establishment of worldwide social networks and international organizations, including businesses.

It is not surprising that the universalization of compassion is documented well as developing in a region of the world where there was substantial and very early exploration and trade- the circum-Mediterranean. Early trading settlements in this area emerged as towns in which Greek, Roman, Jewish, and local people interacted freely in the marketplace. Similar values developed in the East, in the creeds of Buddhism, Taoism, and eventually, the export of gentler forms of Islam to Southeast Asia. However, compassion is often expressed in different ways, using different images, and with different goals (for example, reincarnation). Still, we are a single species, and eastern or preliterate forms of religious thinking remain more similar to western forms than they are different. They all hinge upon fully developed bodies of theory (in oral or written form) about the relationship between humans and the supernatural. It seems that all human groups naturally develop these theories, and again, we ask: Why? How? In modern life, 
we see originally religious values widely in political contexts, and, while the practice of specific religions becomes separated from state-run institutions (like schools), compassion somehow passes the non-sectarian test and is displayed broadly in institutions like hospitals and schools.

We conclude that our exercise of ferreting out a better understanding of compassion from the changes in Biblical texts, has underscored important worldwide historical trends, as well as some psychological consensus that compassion is rational and requires "judgment." And still, what exactly is compassion and how does it look from a neurological perspective? And, how does it follow our understanding of the evolution of the human species?

\section{EVOLUTION OF COMPASSION AS AN ADVANCED COGNITIVE TRAIT}

At the start of our analysis of religious capacity, we noted that our evolutionary model appearing in papers one and two has some very practical uses. We shall demonstrate that utility by reviewing the evolutionary stages of the model in Table 1, and showing how compassion is congruent with religious capacity and why it appears so often with it. Those readers who recall papers one and two will almost immediately begin to see how compassion connects to the evolution of the trait of religious capacity.

The stages in Table 1 can be used to define the parameters of the human trait of religious capacity, but not the accompanying neurological and genomic specifics that support it. When we ask why the ten stages in this table are so important, the answer is that without them, religious capacity would not be what we see today. Without each of these ten evolutionary innovations (usually types, with several examples at the genomic level), religious capacity as a human trait would not exist. Table 1 suggests the complexity at the foundation of human religious capacity, but also how the underpinnings, their emergence, and their expression in religious behavior are interconnected.

This complex totality answers one of the more facile explanations for human religion - that it is a "spandrel” (Pyysiäinen and Hauser 2010; Gould 1979). These authors and others see religion as an assemblage of by-products of other adaptations, not as a functioning whole that serves prosocial, human needs now, and since our species arose. We propose that religious capacity is not a spandrel, and some authors, e.g., Van Slyke (2011) have argued it is not. Religious capacity's "building blocks" are all interconnected, and have been so for millions of years. Nature has not created a "salad," but a very finely seasoned "stew," which loses its meaning when de-constructed, and so it cannot be. Human religious capacity remains a whole.

Let us explore exactly what humans see when they recognize religious capacity and compassion, which is the task we set for ourselves when we began our helpful Biblical analysis. What is so intuitively obvious to humans? What do they see, even when they do not know the language and do not understand the culture? And furthermore, why are strangers able to detect a person "with compassion” within a few seconds (Kogan et al. 2011)? 
Table 3. Experiential Components of Religious Capacity, Organized and Focused After Cultural Neural Reuse

\section{Perception of and Response to a Spiritual Realm}

11. Awe and wonder in response to culturally defined cues

12. Adoration and reverence

II. The Immediate Experience

13. Experience of good feelings when religious expression taps neural reward systems

14. Experience of calm and connectedness with the spiritual, after ritual

15. Experience of reduced anxiety, after religious rituals and events

16. Experience, for some, of hypo-excited or hyper-excited states to interact with the supernatural.

III. Acquiescence

17. Introspection, concentration, and meditation, including self-study and the habit of prayer

18. Transformation of the self above everyday life, achieving a selflessness and being filled with the supernatural periodically

19. Acknowledgment of a spiritual being's transcendence above everything, and therefore encompassing everything

20. Acknowledgment of a spiritual being's immanence in everything, so that what is real and true is adequately defined; feelings of being grounded

21. Acceptance of a religious belief system's rationalization of order, and rules of order, and so feelings of certainty and centeredness

22. Acceptance of humans' place in the universe, as defined by a religious belief system.

\section{Commitment}

23. Alignment, or continual comparison of the self with a system of belief

24. Obedience to serving the spiritual, and living in accordance with it.

Religious capacity is based on features found in all primates, especially their sociality, activity, flexibility, curiosity, and intellect, which date from 55-65 million years ago. Religious capacity evolved in the genus Homo (now, 3 million years old), which emerged out of an ancient ape population whose model stabilized around 19 million years ago with the fully defined ape, Proconsul. Therefore, many characteristics of religious capacity also rely on the features of apes: their size, upright posture while sitting, originally arboreal life, intellect, nurturance of the young, strength, agility, ability to fight when necessary, and, of course, the absence of a tail, which accentuated the need for physical flexibility. We doubt that religious capacity could have emerged on a line of small, retiring, skittish terrestrial mammals. Indeed, we know it did not, 
ever. Such a biology would not have supported it. Apes are "out there" from time to time, strong and demonstrative, as are humans, as is human religious expression, as is compassionate action.

Religious cognition and behavior are strongly dependent on evolutionary upgrades in hearing and sight. These senses allow humans to respond to music and chanting, drum beats, the tinkle of a bell drawing attention to the sacred, a deep and mournful horn summoning the spirits of the mountains, or the wail of lamentation at a funeral service while a loved one is bid good-bye on his or her journey to an afterlife. Few can be unmoved by these sounds. Religious experience depends on the senses, which in turn transport humans experientially to a condition of openness to receive the supernatural, heed admonitions, and transcend everyday life in a feeling of oneness with the spiritual realm. Quite literally, the senses (in concert with the imaginings of the human parietal and frontal lobes) transport religious participants to another, if counter-factual, place that, we propose, is connected to the expansion of the fully globular skull in Homo sapiens.

We should note that, "Neurocranial globularity in our species is due to an early postnatal stage of development characterized by expansion of parietal and cerebellar volume (Neubauer et al. 2009). Interestingly, chimpanzees and Neanderthals lack this ontogenetic stage...” (Bruner et al. 2017, 1054). The difference is also striking between humans and chimpanzees:

...humans and chimpanzee phenotypes are separated with no overlap in their morphological ranges, with humans displaying dilated precuneus and stretched, parieto-occipital areas. (Bruner et al. 2017, 1056).

Therefore, our contention is that there is a relationship between this unique brain architecture and the emergence of the human ability to engage in theological thinking, and we link what we call "religious experience" to it. This emergence involved many human biological systems, not just parietal expansion, but also, as we have noted, the human senses, as well as genetically based types of social sensitivity examined in paper two. As an example, the theological proposition of transcendence is often dependent on the senses, or, interestingly, on their full absence, as in deep meditation. Sensory deprivation and sensory overload have both been used by religions to achieve oneness with the supernatural, and drugs can be used to accentuate either.

Religious capacity has also always been utterly dependent on an evolutionary down-regulation of aggression, beginning 8-10 million years ago. (It has been proposed that there were later evolutionary periods of reduction in aggression after Homo sapiens evolved, MacLean 2016.) These reductions in aggression are fundamental to later religious communities, group rituals, and expressions of compassion. Without a down-regulation of aggression, there would be no assemblages in which humans could gather to experience spiritual connections and learn important lessons detailed in parables, plays, and puppet shows. Even if these same human assemblages are sadly sometimes turned outward in warfare and conquest at the service of charismatic leaders or economic need, the original assemblage required a down-regulation of aggression and an upgrade in social tolerance. Many adult mammals (unless herd animals who gather for protection) have little to do with each other, except for procreative purposes, so the notion of a "religious community" is strongly dependent on adults being tolerant of each other. In some groups of ancient apes giving rise to the human (and bonobo) lines, the level of social tolerance among adults increased and was fixed in the genome. That type of tolerance was originally a juvenile trait, which was then retained developmentally. The need for social tolerance now becomes ever more accentuated in larger and larger communities of humans. 
The emergence of social tolerance leads to a problem, and that is the question of when to be tolerant and when to be aggressive, when to be cooperative and when to speak out with a contrarian voice. Adult higher primates rarely act with complete abandon-without social and cultural consequences. This leads to a precariousness, which has utility when problems arise. Individuals stop to think. The wary ape or early hominin looks away to signal non-belligerence, and sizes up the mood of the group. Since social tolerance among higher apes and early hominins raises the issue of deciding when to be aggressive, we propose that evolutionary processes supported upgrades in both intellect and sensitivity (general and emotional), to assist in making decisions about relative tolerance and aggression.

We propose that these were some of the origins of the complex decision making that later expressions of compassion rely upon so much. It must have been as much as 7-8 million years ago, that the decision-making loops used in compassion began to emerge in a rudimentary way. Evolution of a brain that can decide, according to a system of values, the socially "best" course of action is a stunning evolutionary accomplishment. Add to this, the emergence of protolanguage abilities, and individual decision making emerges and becomes part of group decision making. Indeed, they were never separate for the higher primates. Humans are never alone, even when alone, and if they are truly alone, they go insane. Primates are social and dependent on the group. Ultimately, compassion is a higher cognitive expression of that dependence.

By the time cultural capacity evolved in small populations emerging out of an already reduced population of ancient apes, human ancestors had already become a species in which aggression was reduced. We suggest two results: (1) that the down-regulation of aggression during hominin evolution was one reason that refined human decision making skills were so badly needed, and (2) that cultural capacity was enabled by this down-regulation of aggression. Until that happened, the lengthened period of cultural learning that hominins enjoy could not have evolved. Increased tolerance and longer periods of childrearing (a result of secondary altriciality) were needed in eventually learning the more advanced cognitive traits of the genus Homo.

The down-regulation of aggression also happened to some of the members of the genus Pan (the bonobos), but not others (the chimpanzees). The bonobos did not emerge with strong cognitive problem-solving skills (Hare, Wobber, and Wrangham 2012). Bonobos score lower on cognitive tests than do their cousins, the chimpanzees, who have a much more aggressive orientation. Humans emerged with both good decision-making skills about when to be aggressive, and excellent cognitive problem-solving skills. The traits sorted independently in smaller groups of an already reduced ape population giving rise to both Pan and Homo.

The length of time between cultural capacity's first appearance and the time it came to engulf all social life in the genus Homo is unknown, although we can estimate that culture was beginning to be apparent in Homo habilis at around three million years ago. The fact that Homo habilis made identifiable stone tools strongly suggests that cultural learning was occurring. By the time of Homo erectus, culture and its use of patterns were firmly in place, as we see from the archaeological remains of finely made stone hand axes.

Throughout this time of reduction in aggression, increase in social tolerance, and development of secondary altriciality, upgrades in sensitivity (not perceptual sensations, but increased general reactivity) and intellect were occurring. We reviewed certain genetically determined forms of sensitivity in paper two, including those that engage the amygdala (a center for emotion) and 
those that do not. For example, some forms of genetically determined, increased sensitivity are upgrades in awareness of those close (friends and family) and their emotional states, as well as an awareness of their disposition and a readiness for action to help-all without the involvement of the onlooker's emotion centers in the brain (Acevedo et al. 2014). Again, later expression of compassion is fundamentally keyed to social tolerance and sensitivity to others' needs. Perception and sensitivity led the way to later expressions of compassion.

By the time that moral capacity emerged in a rudimentary way, we propose, in Homo erectus, 12 million years ago, after the species learned to control fire, members of the genus Homo were probably already using the mechanism of cultural neural reuse (defined below) to capture and refine useful cognitive capacities. By the time Homo sapiens emerged, now understood as more slowly, between 400,000-200,000 years ago (Fleagle et al. 2008; Callaway 2014; Hublin et al. 2017), religious capacity was probably in place, evidenced by the round cranial vault of anatomically modern humans, shaped in response to a certain type of expansion of the parietal lobes (Bruner and Iriki 2016; Bruner et al. 2017). The later development of moral and religious capacities emerges as a culturally bound tradition to which compassionate action can be attached. In return, compassionate action is rationalized by moral and religious precepts.

In summary, we propose that religious capacity's frequent companion, compassion, occurs in three cognitive steps that overlap, bounce back and forth, and generally end in a decision on how to react, and whether or not action is taken: (1) perception, (2) sensitivity, and (3) decision making. We propose these cognitive steps of compassion in order of complexity and almost certainly, their order of evolutionary emergence. Endless additional steps can be added while action is further planned or not planned, executed or not executed, received well or not. We should ask: Is compassion present even if action to help does not occur? Yes, we believe it is, as long as actions have been envisioned. They and their evaluation occur rapidly, so once we become aware of these thoughts, they have already happened. However, compassionate decision making remains a human choice and can be changed with additional learning and decisions.

The interpretation of compassion as an adjunct to reduction in aggression, increase in social tolerance, increase in sensitivity, and the longer developmental trajectory occasioned by secondary altriciality makes sense, with only one problem. The decision-making features that so routinely characterize adult, human, cognitive compassion probably were not fully evolved until Homo sapiens. We suggest in paper two that religious capacity only appeared in our species, at 200-400,000 years ago - or even somewhat later, following the latest results on the timing of precuneus expansion. According to an absence of parietal expansion, it did not occur in related species of Homo, such as Homo neanderthalensis. The latter's cranial expansion, in response to the parietal lobes, was mainly laterally, not also front-to-back as in Homo sapiens. Only the latter has a globe-shaped skull so typical of our species (Bruner and Iriki 2016; Bruner et al. 2017).

Therefore, we are quite comfortable seating cognitively defined compassion in our species alone. Does this mean it did not have antecedents in other close ancestral species? No. However, our view is that human compassion is fundamentally one of those advanced cognitive traits that helped hominins decide, once aggression was reduced, when to be receptive and tolerant of others, and whether to help them. Compassion rationalized by culture and religious beliefs makes decision making and compassionate action easier. Others may find fault with one's actions, but less so with the reasons one acted. 
We reviewed in paper two, two genetically based forms of sensitivity (the short variant of the 5HTTLPR and the ADRA2B deletion variant), and we learned that neuroscientists believe many more genes will be discovered that guide different types of sensitivity (Brookshire 2015). Compassion no doubt makes use of several different forms of general sensitivity/reactivity, and they appear in different proportions in different people, for example, those that involve emotion and those that do not, those that are geared only toward people we know and those that are geared toward unknown others. The use especially of both emotion-related and non-emotionrelated genetic capacities in the functioning of compassion presents a mixed phenotypic picture, and as a result, compassion has been a difficult human capability to define clearly-except in religious stories, creeds, and texts, which strongly suggests that compassion is one of those complex human faculties that other humans "know when they see it." (The fact that there appears to be an underlying genetic basis for perception of a "compassionate person" supports this view, Kogan et al. 2011). Indeed, compassion can appear as a moving target, first using some genomic underpinnings and then, at other times, using others. Interestingly, the complexity of compassion's interpretations is shown clearly in biblical texts.

Before we turn to our action example of compassion in early Homo sapiens, we shall introduce a model for understanding the emergence of religious capacity that is based on neural reuse theory. Such a theory may accommodate complex capabilities like religious thinking and compassion better than a non-process list of likely candidate-genes. The following model relies on the action of cultural evolution in redeploying brain structures already operating in neural networks dedicated to other, older tasks. We propose that re-deployed neural networks must have emerged to guide advanced cognitive features like religious capacity and compassion. The model of neural reuse is borrowed from linguistics (Christiansen and Müller 2014) and we modify it for religious capacity and compassion. Unlike some researchers using cultural neural reuse theory, we propose that the process directly impacts the genome, and we give our reasons below.

\section{NEURAL REUSE THEORY}

Neural reuse theory — which subsumes cultural neural reuse theory —is emerging as an important way to address the overlap and joint action of biological and cultural evolution. From our perspective, it helps to explain how complex, higher-level, cognitive capacities, which are driven partly by human cultures, can be understood within a model of Darwinian evolution. The redeployment of neural circuits from their original purposes, so that neural structures come to function in new networks, complements our model of evolutionary stages, in Table 1, especially the later stages. Together, Table 1 and neural reuse theory help to frame the emergence and fixation of religious capacity in the genus Homo, in light of its highly varied phenotypic expression. Indeed, it is worth asking: Can a capacity that produces so much phenotypic variation be considered a biological "trait"? Our answer is yes, and we use cultural neural reuse theory to explain how religious capacity results in so much variability. What is important, as we emphasized in paper two, is that the trait reliably develops. And, it does.

It is not until the later stages of hominin evolution, in which enhanced working memory, external storage of information, visuospatial reckoning with expanded frontal and parietal lobes, and the executive functions of planning and decision making, together allow the emergence of 
theologically-based religious capacity and congruent capabilities such as compassion. If it is true, as we have proposed, that Homo erectus had a rudimentary moral capacity (Rappaport and Corbally 2016a; 2017), then the species also had glimmers of these emerging higher-level functions. Still, they were not fully developed until Homo sapiens.

Neural reuse theory includes a new perspective on the functional architecture of the brain (Anderson 2010). Christiansen and Müller (2014, 677) explain:

Instead of viewing various brain regions as being dedicated to broad cognitive domains such as language, vision, memory, or reasoning, it is proposed that low-level neural circuits that have evolved for one specific purpose are redeployed as part of another neuronal network to accommodate a new function... The basic premise is that reusing existing neural circuits to accomplish a new function is more likely from an evolutionary perspective than evolving a completely new circuit de novo (cf Jacob 1977).

We noted in papers one and two of this series, that evolution is conservative and often tends to take the most efficient path, if not the most likely, due to factors like strong positive selection. The level of functional specialization in the human brain, and between the two hemispheres of the brain, is elementary proof that evolution works with what is present, rather than creating entirely new neural structures to achieve higher cognitive capacities. What the emerging theory of neural reuse is less certain of, at this early stage of its development, is how this happens. Which neural circuits are "chosen" for reuse? Must they be somehow compatible with a specific cognitive capacity? How exactly do they "hook up"? And, how is the emergence of the new circuitry captured and perpetuated by the genome, and so passed on to later generations?

Morten Christiansen and Ralph-Axel Müller (2014) point to sources chronicling the emergence of neural reuse theory, in addition to Anderson's “massive redeployment hypothesis” (2010). These include Vittorio Gallese (2008), Susan Hurley (2008), and Stanislas Dehane and Leonardo Cohen (2007). Indeed, Michael Gazzaniga (1999) has been emphasizing for quite some time that the brain does not constitute a single neural network, but many of them, and they enable cognitive capacities that number perhaps in the "thousands." We understand Christiansen and Müller’s “low-level neural circuits” (2014, 677), some of which include "redeployed” brain structures, as making increasing numbers of cognitive capacities possible, through the combined action of cultural and biological evolution. That is where language, and we suggest, religious capacity come in. Their emergence must have been a very complex and interesting dance indeed, on the neurological and genomic levels.

We hasten to add that some analysts (e.g., D’Ambrosio and Colagè 2017) hold that cultural neural reuse-like the re-deployment of portions of the visual cortex on one side of the brain when humans learn to read-is, when initiated, a function of epigenetics, and so "above" the genome and therefore not involved directly in organic evolution in the same way as genetically based recombination of nuclear material in the gametes. The mechanisms to explain how epigenetics passes on traits, if and when it does, is still emerging. Yet, irrespective of the workings of epigenetics, we propose that neural reuse can, and in fact often does, result in genomic change, primarily because the feedback input by humans in reuse of cognitive traitsthe re-doing, practicing, and tinkering of human activity-changes the cognitive econiche and 
opens up the possibility of altering fitness in a Darwinian sense. This, we believe, is a process of stabilizing a neural network that initially enabled the cognitive skill.

We propose that the mechanism is quite routine, even mundane. Through generation after generation of cognitive reuse, cultural evolution alters the human environment. And, the environment is exactly that to which evolution has always enabled species to adapt. Christiansen and Müller, in their example of the impact of the cultural evolution of language, write: "Processes of cultural evolution involving repeated cycles of learning and use are hypothesized to have shaped language into what we can observe today" $(2014,676)$. They also emphasize the effects of language learning over time can be "adaptation":

It remains possible... that language did have a substantial impact on human genetic evolution... there might be features that are universally stable across linguistic environments (such as the need for enhanced memory capacity or complex pragmatic inferences; Givón \& Malle 2002) that might lead to biological adaptation (Christiansen, Reali \& Chater, 2011).

We propose that neural reuse (including cultural neural reuse) can gradually change the genome and affect the evolutionary process directly by placing advanced cognitive skills under the direct pressure of natural selection, or, through the mechanism of genetic drift whereby genomic material is retained because of small population size and inbreeding. The former effects are directional and the latter effects are random, but both can help to capture advanced cognitive skills. Daniel Matute (2013) emphasizes the ability of genetic drift to affect behavior as well as physical traits. When humans alter their environment through repeated use of culturally constructed, advanced cognitive skills, and brain structures are redeployed that may be predisposed to guide certain actions because the original function was similar, or related, then this opens up the possibility that neural reuse affects fitness. If neural reuse affects fitness, then natural selection becomes possible, especially if it functions in concert with genetic drift in small hominin populations. This type of fitness certainly seems more covert than abilities to stalk game, out-run predators, or produce high sperm counts, but it is conceivable that cognitive skills were so important in the evolution of the genus Homo, they altered fitness in a traditional sense, especially in the context of small populations, where genetic drift could also operate. Christiansen, Reali and Chater $(2011,247)$ confirm this with respect to language:

...previously learned linguistic features might become innate through natural selection across many generations of language users. The results indicate that cultural evolution of language does not necessarily prevent functional features of language from becoming genetically fixed, thus potentially providing a particularly informative source of constraints on cross-linguistic resemblance patterns.

These are precisely the mechanisms that we propose fix religious capacity in a multiplicity of human cultures, so that they resemble each other both in general evolutionary terms (Table 1), and also in some specific features that can be identified as "religious expression" even crossculturally (Table 3). The similarities of human religious expressions are sufficiently striking that they suggest the same neural substrates were redeployed repeatedly by cultural neural reuse. 
Let us revisit paleoneurologists Emiliano Bruner and Atsushi Iriki's words on the ability of humans to alter their socio-cognitive niche. They refer to the "triggering" of extra-genetic or epigenetic factors, but our reading of their words does not seem to preclude eventual change of the genome, itself.

Once a novel, alternative, and bistable state is associated with increased fitness, additional resources will be invested to stabilize the system, probably generating further redundancy. Humans can induce such a loop directly and actively, shaping a more comfortable environmental niche. Indeed, human-specific cognitive characteristics seem to be subserved mainly by these "expanded" parietal areas... Subsequently, triggered by extra-genetic or epigenetic factors embedded in such an environment, the corresponding neural niche in the brain could be reinforced further, generating a recursive intentional niche construction... (Bruner and Iriki 2016, 103)

We do not see how the fine functional specializations of the brain, which are created in neural reuse, are continued — fixed — without some natural selection and/or genetic drift, which change the genome, itself. To use Colagè's example (2015) of the right and left FG2 brain tissues, we propose that they may look alike and function alike if reading is not initiated, but in fact they are not exactly alike. Otherwise, there would be random assignment of reading to either the right or left FG2. This apparently does not occur; it is always the left FG2 that involves reading (Colagè 2015; cf Caspers et al. 2014).

Our proposal that neural reuse theory includes alteration of the genome relies on the function of genetic drift at the same time as natural selection. Advanced cognitive capacities can become fixed without strong positive selection in small populations. We have seen in papers one and two of this series that the two mechanisms can work together (Matute 2013). Genetic drift in small populations of early humans could well have allowed non-utilitarian material to remain in the genome and become fixed because of the inbreeding in small populations. There are vast quantities of "neutral" material in the human genome, compared, for example, to the chimpanzee (Lachance and Tishkoff 2013, 136). Humans have much more material that has not been positively selected, and we believe this is due to the severely reduced population sizes of ancient apes and hominins, in which genetic drift was an important determinant of the genomic material that became fixed. Neutral and slightly deleterious material can be retained, with or without some follow-on positive selection (Matute 2013), and this material could have been used in the fixation of reused neural circuits. Without the strong pressure of natural selection (which is weaker in small populations), neural structures could have had more flexibility in their response to the use of cognitive skills. This could have been an enormous advantage for species on the human line.

Finally, culturally guided reuse of brain structures to enable new circuits supporting advanced cognitive traits could be seen as a heritable trait, itself, much like plasticity was not only a facilitator for the development of higher cognitive skills, but a heritable trait, itself. One could argue that natural selection was exerting a type of pressure on neural reuse, itself. In light of the quantities of genetic material allowed to remain in the human genome by genetic drift and the accommodation of slightly deleterious genes (which sometimes become advantageous in a later socio-cognitive niche), one could tentatively suggest that the human line was ready-made to 
capture and perpetuate advanced cognitive skills in the genome and factors that facilitated their learning, through neural reuse. Furthermore, we propose that neural reuse does not operate indiscriminately on random genetic (or epigenetic) material, but is guided, itself, by the utility of the cognitive capacity being reused and the nature and functions of re-deployed neural structures. Ultimately, we propose the conduciveness of neural structures to reuse is not random, but that reuse selects for similarities that we see in religious expression worldwide. In this way, just as languages accommodated themselves to the existing brain structure, religious capacity also molded itself to existing neural networks, reused some for later purposes, and left others alone to accomplish their more ancient purposes.

The history of our species included millions of years in which biological evolution was the key to survival and cultural evolution had not yet emerged. We propose that a capacity for culture evolved biologically, in a rudimentary way, around 8-10 million years ago. Through independent assortment, it emerged differentially in various branches of reduced populations of the higher African apes. The australopithecines (who still had the limb proportions of apes) had a limited cultural repertoire, as did early members of the genus Homo, like Homo habilis, who, while small, evolved with the longer legs and shorter arms more characteristic of modern humans. Today, we see glimmers of cultural capacity in modern chimpanzees and bonobos. On our evolutionary line, culture became overwhelmingly important, penetrating every aspect of social life until it eventually fed into the process of evolution and could change it.

Christiansen and Müller’s language theory suggests that “low-level neural circuits” were redeployed as part of other neural networks to accommodate new cognitive capacities. We propose that this ability to influence the evolution of one's own species by exercising (and reexercising, for generations) higher cognitive capacities, guided by cultural patterns, highlights the extraordinary strength of cultural capacity when it is shared in human groups.

As a mechanism, cultural neural reuse could not have emerged and been effective until culture was present and higher cognitive capacities were emerging, along with the executive functions of planning, decision making, excellent visuospatial reckoning, and external storage of data. We have seen clam shells marked with abstract patterns by Homo erectus at 500,000 years ago (Joordens et al. 2015; Callaway 2014). It appears that the hominin line was on track to develop external storage devices to capture information this long ago, perhaps earlier. And yet, there are no similar finds until we reach Homo sapiens. This may be due to the thinness of the archaeological record. However, our view is that higher cognitive capacities such as language, art, religion, and science had to emerge in a context of other traits that made the species ready to use them. Until Homo sapiens emerged, the cognitive capacity for recording on, and decorating shells, ochres, and stones with engravings and incisings was perhaps not quite "ready for prime time.” It makes very good sense that evolution is uneven in the emergence of traits that came together to enhance hominin life-especially complex cognitive capacities.

The theory of neural reuse relies in part on research in cognitive neuroscience, which reveals the parts of the brain that are active when humans engage in specific cognitive tasks and experience certain cognitive states related to language, writing, science, technology, art, and religion.

Christiansen and Müller (2014) develop a model of the evolution of language through cultural 
accommodation to existing neural structures and redeployment of some in new neural circuits. They propose that culture works with the available neural circuitry, not the other way around. Language theory has been laboring since the 1970s under the notion that there certainly must be a "universal grammar" for all languages because of their similarities. Cultural neural reuse provides a logical reason for the similarities seen among human languages, without having to call upon a "universal grammar." Dispersed groups of early hominins made use of the same brain structures, in some of the same ways, so languages of different groups emerged with similarities. We propose that culture uses tissues that are perhaps already pre-disposed to accomplish similar tasks, and we agree with Christiansen and Müller $(2014,677)$ that culture is no doubt molded reciprocally by accommodation to existing neural structures. They write:

The idea of language as shaped by cultural evolution to fit preexisting constraints from the human brain also promises to simplify the problem of language acquisition. When children acquire their native language(s), their biases will be the right biases because language has been optimized by past generations of learners to fit those very biases (Chater and Christiansen 2010; Zuidema 2003).

Of great interest is the fact that there have been few suggestions of an analogous, genetically based, structural mechanism like a universal grammar for religious capacity. Our Table 1 provides a sequence of genetic innovations through time, and both a rationale and a foundation for much of what we see in modern religions. However, it does not completely characterize religious behavioral expression. To supplement Table 1, we list in Table 3 some of the features of human religious expression, which others have explored so well (e.g., Mithen 1996, 2009; Whitehouse 2004; Watts and Turner 2014). We propose that the sequence in Table 1 is the evolutionary groundwork for the experiential features in Table 3. Table 1 is incomplete without the meaning, sensation of well-being, experience of transcendence and immanence at times, and a confirmation of one's place in the universe-all of which religious belief and expression provide routinely. Many others have written on this type of characterization of religious behavior, but have skipped over its evolutionary foundation, which is outlined in Table 1 and explored in this series of papers. For that reason, they are sometimes left with explanations of "spandrel" because it was not clear how very long the foundations of religious capacity have been interconnected.

We propose that the features in Table 3 are human behaviors and cognitive states that are focused and re-organized by cultural neural reuse into new neural circuits. We suggest that these behaviors and cognitive states can sometimes occur as altered states of consciousness in response to other experiences and to drugs, but, that religious expression organizes and legitimizes them so humans can take advantage of their benefits in confronting life's routine and extraordinary difficulties. In legitimizing them, the experiential features in Table 3 usually do not become over-used and addictive, but remain socially controlled and beneficial. If they do not operate generally for the benefit of human well-being, then we do not believe they should be characterized as "religious."

Culture combines the evolutionary foundation in Table 1 and human expressions and capacities in Table 3, and rationalizes it all into an integrated set of precepts to teach younger members of a cultural group what is real, what is morally right, how to make decisions - and not least of all, 
how to achieve emotionally stimulating, satisfying, but legitimate states of consciousness. Religious cognitive and experiential features, in providing a set of obvious signs for identifying right from wrong, also provide internal cues to help humans make very difficult decisions, especially when the "right thing to do" is not always patently obvious. Life's ambiguities and contradictions are encompassed, resolved, or accepted through all the features in Table 3, at least to a degree.

Our model suggests that cultural neural reuse has, again and again, redeployed some of the same neural substrates to produce types of expression that are identifiable as "religious" by all adult humans. We suggest that this identification hinges upon cultural reuse of the same neural substrates and redeployment of them to form new neural circuits in many of the same ways-just as Christiansen and Müller (2014) suggest for language. Cultural neural reuse has taken a foundation of neural substrates, crafted a type of experience based on new circuitry, which becomes common within and among individual cultures. Within those cultures, religious beliefs are made real, acceptable, and comforting. The process produces a synthesis that, while specific, is identifiable to everyone, even when viewed cross-culturally. Voodoo, santería, and candomblé include types of expressions that many readers might not find comfortable for themselves, but at the same time, they recognize that they express religious beliefs, indeed a syncretism of West African beliefs in spirits with Roman Catholicism.

Table 1 illustrates how the species was set up to accomplish some very complex mental work. Our contention is that this work, in cultural groups with complex social structures, could not be accomplished without the evolutionary history that we explore throughout these three papers. It was not a likely evolutionary development in any other species yet identified on Earth.

The neuroscience of the individual features in Table 3 has been the subject of a goodly amount of research, but rarely, if ever, as an integrated whole. Research is widely scattered in the medical, neurological, psychological, sociological, and anthropological literatures. While the cognitive science of religion - a relatively new field - has attempted to compile and integrate these efforts, they remain, in our view, a jumble of confusing interpretations. For example, we suggest that the addictive potential of many of the features in Table 3 has cast a pall over organized research on them. No one wants to agree with Karl Marx that religion is "the opium of the people," no matter how much truth there might be in that statement. Note that we often acknowledge the addictive and obsessive qualities of video games, talking endlessly, television viewing, and certain kinds of grooming (viewed more clearly in the dog's "paw lick" or the horse's “cribbing”). Yet, many people find it difficult to acknowledge the addictive and obsessive qualities of religious activities_the excesses of cults, excepted.

We propose that cultural neural reuse could help organize the integration of neuroscientific research, by focusing on neural structures, and both the old and new neural circuits, rather than individual experiential features of religious expression. Our contention is that religious thinking and expression are easily distinguishable from, for example, trichotillomania or oxycodone abuse. In the latter, there are no built-in mechanisms for curbing excesses, except death. However, most culturally-based religious belief systems include curbs, limits, rules, leadership, and mechanisms for redress when excesses arise-although there are numerous examples of their coming too late to avoid terrible abuse. The goals also differ. The goal of drug abuse is to 
achieve a high and escape the realities of life, and the goal of genetically based obsessivecompulsive behavior is to reduce anxiety. The goals of religious expression are largely prosocial. That differentiation can well distinguish devotion from addiction and neurosis. Marx was right; but Marx was wrong.

Recent neuroscientific research with brain scans investigates the mechanisms whereby religious thoughts "trigger" reward systems, much like love and drugs do the same (Ferguson et al. 2016). Lisa Miller et al. (2014) discuss the "neuroanatomical correlates" of religious and spiritual experience, especially with respect to prevention of depression in adults. Chad Forbes and Jordan Grafman (2013) write about a second phase of "social neuroscience," and do two important things. They point to the importance of linking up neuroscience to the genomic level; and, they focus on neural circuitry in "assessing interactions between neural regions." The latter will be especially important in discussions of cultural neural reuse and the new circuitry it organizes.

New fields have emerged to try to integrate the widely scattered neuroscientific results on religious experience, especially its relation to sociality. The new fields of "neurotheology" (e.g., Newberg 2010) and "social genomics" (e.g., Cole 2013) both have a role in sorting out the multiple origins and phenotypic expressions of religious capacity. Researchers in social genomics have, for example, examined the effects of isolation and rejection on genes and clusters of them (Cacioppo and Hawkley 2009), and Robinson, Fernald, and Clayton (2008) ask: "What genes and regulatory sequences contribute to the organization and functioning of neural circuits and molecular pathways in the brain that support social behavior?” That issue is important in determining how exactly neural reuse operates to change neural circuits. Yet another field, neurotheology, also called "spiritual neuroscience," focuses on neural structures and networks, and their patterns in brain scans, for example, rather than mental states from a psychological perspective.

The oneness that humans may experience with others practicing different religions comes very close to our universalization of compassion, which we derived from our biblical analysis. In terms of neuroscience, compassion can be viewed, as we noted, according to its three steps: (1) perceptual sensations (upgrades in the senses), (2) genetically based social sensitivity (reactivity), and (3) decision making. We reviewed the genomic and evolutionary origins of (1) and (2) in the first two papers in this series. Here, we explore compassionate decision making, i.e., the human mental work accomplished in order to arrive at a conclusion that another human (sometimes another animal) requires compassionate assistance, and how to react to that need.

One's culture teaches the later stages of decision making, but these can be unlearned and other factors learned, so that different decisions can be forthcoming. Within a single cultural context, compassion tends to originate in the "center" of a person's being and core values. Compassion's origins are "deep," and we saw this clearly in the biblical history of the word's use. This centrality is expressed in various ways in different cultures, as is its deployment outward in action.

We shall address (3) decision making briefly, but first we give an example of "Religious Capacity in Action" in early Homo sapiens, around 150,000 years ago, when our species seems to have appeared with a firm, fixed globular skull (Bruner et al. 2017; Bruner and Pearson 2013). 
We have chosen that date because the protagonist in our story engages in religious thinking in a fully modern way. If our thesis is correct, this individual required a fully expanded precuneus to engage in that thinking.

The action is located at a site not unlike Jebel Irhoud in present-day Morocco, where new remains of early members of our species were recently found at a date that is yet 150,000 years earlier, or more (Hublin 2017 et al.; Callaway 2014). In the action of this early Homo sapiens extended family, compassion appears as a feature concomitant to religious belief, like charity and forgiveness are now—although each of these three "religious companions" has been universalized in modern complex societies where religious beliefs vary so much.

Nevertheless, compassion's three steps (perception, sensitivity, and decision making) can still be seen in the following example of "Religious Capacity in Action." We view an early, extended family of Homo sapiens caught in a tragic bind and they struggle to find a way to go on.

\section{RELIGIOUS CAPACITY IN ACTION: THE STORY OF BO 150,000 YEARS AGO IN NORTH AFRICA}

This is a love story, but not the usual kind. Bo and Leela had known they would be mates since they were children. Bo was a tall, strong, and formidable hunter. She was almost beautiful in profile and the happy sort, endlessly encouraging Bo and their four healthy children. Two of the boys already found mates and the only girl had a suitor from the "opposite band"-the other group of one hundred and fifty of their kind, who mirrored their annual trek from valley to mountains and back again, on the other side of the river.

With a touch of gray in his hair and beard, and the keen eye of a hunter, Bo looked northward to the sea and thought back to his and his brother Girwan's fishing expeditions last year at the mouth of the river whose shores now held their encampment. What fun they had!

Now, the days were getting cooler and the sun's journey swifter. Bo nodded to himself, feeling almost peaceful today, quite sure that they would have enough food for the coming winter. They had dried meat from the summer hunts and fish from the sea this winter.

He glanced at Leela and smiled. Her belly grew large with child and it affected her balance a bit. His smile widened to a grin and he laughed quietly.

She looked at him quizzically and returned the smile.

They were both surprised and happy by the pregnancy because Leela was getting a little old to have children. This would surely be her last.

And that reminded him again of his brother, Girwan. The mountain sprits gifted Leela with four successful pregnancies, now five, but the wife of his brother had none. Ansu lost baby after baby, and this summer, she almost made it to eight months, then lost a little girl who lived only a day. Ansu had not spoken since that day. Leela said she was swollen with milk, and uncomfortable. 
Bo took his brother to his favorite fishing spot to cheer him up, but found him inconsolable.

“She will not speak,” his brother Girwan lamented.

"Leela said she is sad. She will recover."

"I'm not so sure. She is older than Leela. Maybe she has no more chances!" Girwan's expression was desperate and baffled all at once.

The two men returned to their campfires, which sat side by side. They came upon the two women, Ansu crying endlessly while Leela held her tight.

None of the four of them knew how to go on from this catastrophe.

Bo lay down his fish for Leela to clean, and gathered his spear and some food for a journey.

The other three stared at him.

"I'll speak with the mountain spirits tonight, and return tomorrow."

Girwan went to him, "I should go with you, brother."

Bo shook his head and left without another word. He needed to think. A plan was forming, but it would take Leela's agreement, and he wasn't sure she would give it. He wasn't even sure it was the right thing to do.

He walked with a step still quick and sure, toward the mountains to the southwest. He knew the route well, but had never taken it for this purpose.

He stopped short on his route, just after he reached the first hill, and began to feel more peaceful. Before today, he had not known how to help Girwan and his wife Ansu. Still, he needed to ask permission from the spirits of the mountains, especially the one that he called, "Old Man." He spoke to him from time to time when he was hunting for food to feed the band. Bo was unparalleled with a spear, but he still needed Old Man's blessing in the hunt.

An evening breeze arose. Old Man spoke to him on the wind and told him he understood his disquiet.

Bo sat back next to a rock prominence he'd visited before. "I do not know what's right. I do not know if she will agree. Will she blame me? ... and then, will she forgive me?"

"Ask her!” came the answer on the wind.

"I love them all. I can't bear to see Girwan and Ansu so unhappy, not when I can do something." 
"Ask her!" the voice came again on the wind. "You will know in your heart the right thing to do. You will see. Love has many paths.”

"I'll ask," Bo nodded, and wiped away the tears from his face. It would be a loss to him, too, and their other children, but perhaps well worth it. Would the children understand? Yes, they were getting old enough to understand. He and Leela had raised them well.

Bo ate some of the jerky he brought, and lay back against the large smooth rock. His eyes closed and he dreamed of a small gazelle who was frolicking around him. The gazelle darted away, but then came back. He waited, and the gazelle ran away again, and then came back. He looked carefully to see if it was a male or female. He couldn't tell! And, instead of feeling frustrated, he laughed in his dream, and the laughing woke him up.

He returned to the campfire and asked the hardest question he'd ever asked of his beautiful wife Leela.

She wept, but then she smiled and nodded.

"It's the only answer, Leela."

She nodded, "Yes."

And so, when Leela came to term less than a week later, Bo took the small healthy child, a female, and handed her to his brother Girwan.

Girwan broke down weeping, shaking his head. "You give her to Ansu. You must.”

Bo walked to Ansu and handed the little girl to her new mother. "The spirits of the mountains commanded me, and I must obey. She is yours to love. We will never be far away."

\section{DECISION MAKING FOR COMPASSIONATE ACTION}

The first two of our three cognitive steps of compassion (upgraded perceptions, and geneticallybased sensitivity) are simplified in this Story of Bo. Perceptual sensation of Ansu and Girwan's sad losses was unavoidable by the family members living near them. They knew Ansu wept, and they knew she had not spoken since the death of her baby. Because Ansu and Girwan were close relations and in fact neighbors of Bo and Leela, the issue of social sensitivity to strangers vs. family is less of an issue in this case, although Bo's potential for having the genes for both types of sensitivity that we discussed in paper two (the short variant of the 5-HTTLPR and the ADRA2B deletion variant) would affect his perception of Girwan and Ansu's problems, and they could cause him to become deeply involved, along with other factors. Still, as we noted in paper two, there are sure to be additional genes for innate sensitivity discovered, and they all work together. Given Bo's attunement to the difficulties of his brother, we might guess that he has substantial, innate ability to pick up on the problem. 
However, in tracing out our three cognitive steps involved in compassion, it is the issue of decision making that catches our attention and makes us wonder: Did Bo make the right decision? Indeed, was there a "correct” decision, or was Bo caught in a situation where there was no possible way to avoid heartbreak of one sort or another? Let us take a look at some modern research that is beginning to elucidate the factors involved in compassionate decision making.

For those readers who are interested in the genetic basis for "prosocial behavior," which we interpret as including religious behavior and compassionate action, Christopher C. Conway and George M. Slavich's review in Paul Gilbert's Compassion: Concepts, Research and Application (2017) is a good place to start. As with general sensitivity, new genes and their mechanisms of action are being discovered routinely in the field of "quantitative genetics" and more specifically, the "molecular genetics of prosocial behavior." Conway and Slavich report, for example, that:

Oxytocin (OT) and arginine vasopressin (AVP) are neuropeptides... thought to regulate the propensity to engage in affiliative behaviors involving compassion, perspective taking, empathy, and trust (see Ebstein, Knafo, Mankuta, Chew, and San Lai, 2012). ...A main focus of this work has been on examining links between prosociality and polymorphisms in the gene that encodes the oxytocin receptor... There are many locations in the oxytocin receptor gene (abbreviated OXTR) where the DNA code varies across people (2017, 157-8).

Indeed, a relationship between religion and oxytocin (known as the "love hormone" that can ostensibly "increase spirituality") is one of the better known, general results from this field, and explains, to an extent, why religious behavior is used to cope with difficulties and the distress they cause. Religious behavior makes people feel better, perhaps in part because it increases oxytocin production. In one study, Joni Sasaki, Taraneh Mojavereian, and Heejung Kim report interesting results that individuals have different genotypes for the oxytocin receptor gene, and these differences account for some orientation toward human sociality. "The results showed that experimentally priming religion increased self-control behaviors for people with GG genotypes more than people with AA/AG genotypes." The authors point out that results integrate "genetic moderation and social psychological approaches...” (2015, 97). Indeed, combining approaches for social, clinical, and developmental psychology is extremely important in teasing apart the effects of various genes in social contexts - and then, testing all results and theories crossculturally, which brings in medical anthropology. The complexity and creativity of research designs to understand the genetics of religious capacity and compassion will only increase in the future. The identification of genes that promote prosociality and its relations to religious behavior is only now just beginning. A more indepth treatment of these results for our model of the evolution of religious capacity will be forthcoming in book form soon.

Before we go on to discuss Bo’s Story, we shall mention one more interesting result related to oxytocin because it suggests a type of human sociality that is not altogether within conscious control and may be valid cross-culturally. Aleksandr Kogan et al. (2011, 19189) write that,

Individuals who are homozygous for the G allele of the rs53576 SNP of the oxytocin receptor (OXTR) gene tend to be more prosocial than carriers of the A allele. However, 
little is known about how these differences manifest behaviorally and whether they are readily detectable by outside observers, both critical questions in theoretical accounts of prosociality. ... we found that individuals homozygous for the $\mathrm{G}$ allele were judged to be more prosocial than carriers of the A allele. These differences were completely accounted for by variations in the expression of affiliative cues.

The relationship between self-control and religious participation, noted above, is an interesting factor in the Story of Bo and the decision he was making that might lead to compassion and compassionate action. Bo exhibits a substantial amount of self-control in the little story. First, by trying one solution, then seeking another. Finally, he goes away to another place (a feature of moral decision making, too) and a different state of mind to seek confirmation on what to do. Bo's distress about his brother and sister-in-law led him to try to alleviate Girwan's distress first through recreation (fishing), but he found it did not quite accomplish his goal. His distress then led him to seek a type of religious counsel. Finally, he sought agreement in his social group.

In trying to decide what to do, Bo removed himself from his social group, to seek guidance from a supernatural realm. He sequestered himself in a special place (an aspect of religious capacity that we propose it takes from the earlier emergence of moral capacity). Then, he entered a state that we might call meditation or prayer, where he asked questions of a trusted spiritual force, and received answers. This is such a common occurrence in the everyday life of so many humans, it is difficult to call it an altered state of consciousness. On a lone walk or in the privacy of our bedroom, we can ask, “Oh, God, what should I do?” We whisper these short prayers or recite them to ourselves, but we never lose consciousness. In our view, there is a range of prayerful and meditative states, and the range extends into an altered state. In this case, Bo slept and he dreamed. It could easily have been confusing, but it was not. It was a happy dream, and he laughed. That was a clear sign he was resolved to what he had to do, and the initial stage of decision making was complete. Later stages included his wife, as well as Girwan (who could have refused the infant), and Girwan's wife Ansu (who could also have refused, saying, "Oh, I can’t let you do that!”)

In teasing apart the steps of compassionate decision making we searched for other models, and found a recent study that lays bare an important aspect of decision making. The question has been a research issue for quite some time: Do people, when deciding on a choice, remember generalized overviews of past experiences (the "prototype theory"), or, do they recall specific representations of individual experiences (the "exemplar theory")? Michael Mack, Alison Preston, and Bradley Love (2013), using computer simulations and brain-imaging results, concluded that the exemplar theory fits their data best. Specific memories are more important that abstractions of experiences.

However, many existing models of compassionate decision making tend to reduce variables to loops involving so-called emotions, rewards, costs, and benefits, none of which we find sufficient for a full model. The value system upon which Bo made his decision was largely preexisting in his brain (but certainly not innate). Value-based decision making tends to use many factors, including emotions and recall of past events, well before the final collapse of options in neuronal maps into a single choice and eventual making of a decision (see Glimcher below). 
In the slower, values-based decision making process we see in the story, Bo thinks back to the good times he had with his brother Girwan, on last year's fishing expeditions. This could accentuate a contrast with his brother's current state of distress and bewilderment, and the contrast might hasten Bo's decision making by emphasizing the difference in his brother's two emotional states. However, these past activities also well illustrate the values Bo lived with, including care for his brother and family. Compassionate action is based especially on an estimation of how "things ought to be," and one source of information (not the only one) is past history and the values one used in the past.

Paul Glimcher, in a chapter on, “The Emerging Standard Model of the Human Decision-Making Apparatus,” outlines the basic human and monkey apparatus of value-based decision-making. He writes (2014, 683):

...it is now known that a set of frontal cortical and basal ganglia store and represent the idiosyncratic values we place on all kinds of things. This value system, a complex of many areas, synthesizes a single common representation of the values of all the many choice options that we face at any given moment. These so-called subjective values are then sent to a set of frontal and parietal areas that actually perform the choice process.

As our final task in this paper, let us focus for a moment on the brain's “parietal areas” that take part in this operation. Our goal is to understand some of the functions of the parietal lobes, the intraparietal sulcus, and perhaps the precuneus, in the emergence of thinking that might be termed “modern." We note that psychologist Frederick Coolidge and anthropologist Thomas Wynn (2009) were early in their identification of the parietal lobes, and in particular, the intraparietal sulcus, as implicated in modern thinking that emerged on the hominin line. We also note the expansion of the parietal lobes, in particular the precuneus, in Bruner and colleagues' interpretations of the skulls of Homo sapiens vs. Homo neaderthalensis (Bruner and Iriki 2016; Bruner et al. 2017). They propose that it is the front-to-back expansion of the parietal lobes, and more specifically, the precuneus, that account for the fully globular skull of modern humans.

We ask: What are some of the latest findings on the parietals that might point toward a fundamental importance and change that could be connected to modern thinking? Melina Uncapher, Alan Gordon, and Anthony Wagner (2014), who summarize "Parietal Lobe Mechanisms Subserving Episodic Memory Retrieval,” point to the importance of the parietals for episodic memory, i.e., the conscious remembering of past events and recognition of things previously encountered $(2014,567)$. Their “working model” of posterior parietal cortex (PPC) operations during episodic retrieval illustrates the importance of the intraparietal sulcus in topdown attention, evidence accumulation, and action intention (manual and oculomotor) (2014, 571). One can see how these processes are just as important for scientific modeling and artistic creativity, as they are for decision making on issues related to moral and religious questions ( $c f$ Rappaport and Corbally 2015; 2016b).

Glimcher gives an overview of a standard model for value-based decision making and refers to “The Choice Circuit” (2014, 683-686), which is followed by “The Valuation Circuit” (2014, 686-689). The model includes the neural circuits that make choices, "once an internal representation of the values of the options under consideration has already been expressed with 
the nervous system” (2014, 683). He assumes that values lie upon a single common scale (684). One of his major questions is: How are subjective values encoded in a choice circuit? Information in the cerebral cortex is encoded in useful, two-dimensional "topographic maps" that reflect rates of neuronal firing. The best-valued choice appears with the highest peak in the map (Glimcher 2014, 683-4). The maps are used to envision (in this example) two different options in a decision, and finally, a cascade of topographic maps when a decision is made $(2014,686)$. Note that the classical example he cites, fully involves the lateral intraparietal area (Gnadt and Andersen 1988).

Glimcher presents a figure of the interconnected cascade of topographic maps that represent derivation of the values of a current option and execution of the choice process, at least for simple, orienting eye-movement decision making. Whenever the values of two options get close to one another in the choice process, neuronal "noise" results in what he calls a "winner-take-all process.” So, variability emerges as a key feature of the operation of this network where neuronal firings are basically random. $(2014,686)$. He clearly identifies the "choice areas" for decision making:

... (Newsome, Britten, Salzman \& Movshon, 1990). Their studies suggest that perceptual signals originating in the extrastriate visual cortex's area MT [middle temporal] are passed to area LIP [lateral intraparietal area], the frontal eye fields, and the superior colliculus for decision making. As we have seen in this chapter, these three areas are known as choice areas in value-based decision-making models. So what does this mean? Do these choice areas do two different jobs, one value-related and one perceptionrelated? Or is an integrated view of value-based and perceptual-based decision making possible? (Glimcher 2014, 689)

Glimcher confirms that there is growing integration of different models of decision making. "Both the value-based [slower] and perceptual [faster] decision-making traditions have identified the frontal and parietal choice areas as a key stage in many kinds of decision making... What this suggests is a tremendous degree of unity. It suggests that the so-called choice circuits can operate on a broad range of inputs to produce coherent behavior under many circumstances" $(2014,689)$. He asks: "Can the same neural systems using the same computational properties, produce both behaviors?” (2014, 689)

He then answers this question and describes the commonality:

Soltani and colleagues (Soltani \& Wang, 2008) were the first scholars to demonstrate that the answer to that question is an unambiguous yes. The same circuits really can perform both of these functions. What Soltani and colleagues demonstrated is that what differs between these two classes of models comes down to the inhibitory-excitatory balance of the network as the choice process progresses. In temporally discrete value-based decision making, the network begins in a very noncompetitive mode... When a choice is made, changes in the excitatory-inhibitory balance of the network cause the peaks of activity to compete, implementing the winner-take-all process. In dynamic perceptual decision making, in contrast, the inhibitory-excitatory balance of the network can be thought of as preset, so some degree of competition is always present. This preset balance means that 
as soon as some critical level of evidence is achieved, the network automatically converges to a single choice” $(2014,689)$.

He ends by noting, “...what is important is that the two classes of models are now really beginning to fit together...” $(2014,689)$. This is important for those of us trying to understand the similarities in decision making and modeling in religious, scientific, and artistic contexts (Rappaport and Corbally 2015; 2016b). What we gain from Glimcher and the colleagues he cites is insight that different types of decision making use a basic computational process.

Is the process that Glimcher describes what is going on in Bo's brain? Bo certainly was making a values-based decision, and the value system that it was based upon seems solid, since we read that he and Leela raised their (now successful, near-adult) children well. Bo was generous with his family, and he received a great deal of encouragement from that family. All this suggests he was in a situation to make a costly decision for the sake of two other people, his brother Girwan and wife Ansu. What we have in Glimcher's description of the neuronal decision-making process is an internal picture of what was happening in Bo's brain as he made a difficult, costly, but loving decision that allowed them all to go on, with hope and faith in the future. They all gained, even Bo, and the losses he and he wife sustained were balanced by sufficient rewards to make his decision comprehensible. His decision was one of Glimcher's slower, value-based decisions, but a difficult one.

To bring our work back around to a theme we have addressed before, one should note that the most important neural structures in decision making include the parietal areas. Therefore, we end this third paper with a parallel conclusion to the second paper's: The parietal lobes had something very important to do with the transition to modern thinking in only one species in the genus Homo- our species. In paper two we see this suggested by the shape of the cranial vault. Here, we emphasize the connection Bruner and colleagues make between this shape and higher cognitive functions:

The medial parietal cortex is also implicated in higher cognitive processes such as autobiographic memory retrieval, theory of mind and self-reflection (Cavanna and Trimble 2006; Schneider et al. 2014). [Bruner et al. 2017, 1057]

We contend that theological thinking is fully involved with - even dependent upon - the human brain's ability to manipulate autobiographical information, with a theory of mind of the self and of others, and with an ability to reflect on differences between the self and others. We have seen in this last section that the parietal lobes are important in the type of slow, intricate (as well as perceptual, fast-moving) decision making that we propose is characteristic of our species alone, although it is based on a primate model. Bo's decision was made with the aid of a values systems that was reinforced by his belief in the supernatural, and advice he received from the "Old Man." Our view is that, however sophisticated humans become while they continue to evolve, it seems probable that many will continue to rely on values-based systems symbolized in theologicallybased religious beliefs and behavior. The precuneus will continue to support religious capacity. What we cannot envision yet is what other traits may be supported by the same brain capacities, or even new ones, as cultural evolution continues to affect, through neural reuse, the expansion of new neural circuits. 


\section{REFERENCES}

Acevedo, Bianca P., Elaine N. Aron, Arthur Aron, Matthew-Donald Sangster, Nancy Collins, and Lucy L. Brown. 2014. "The Highly Sensitive Brain: An fMRI Study of Sensory Processing Sensitivity and Response to Others' Emotions.” Brain and Behavior 4(4): 580-594.

Anderson, Michael L. 2010. "Neural reuse: A fundamental Organizational Principle of the Brain.” Behavioral and Brain Sciences 33: 245-313.

Begun, David R. 2016. The Real Planet of the Apes; A New Story of Human Origins. Princeton: Princeton University Press.

Brookshire, Bethany. 2015. “A Vivid Emotional Experience Requires the Right Genetics.” Scicurious (Neuroscience). Online, May 8.

Bruner, Emiliano, and Osbjorn Pearson. 2013. "Neurocranial Evolution in Modern Humans: The Case of Jebel Irhoud 1.” Anthropological Sciences 121: 31-41.

Bruner, Emiliano, and Atsushi Iriki. 2016. "Extending Mind, Visuospatial Integration, and the Evolution of the Parietal Lobes in the Human Genus.” Quaternary International 405: 98-110.

Bruner, Emiliano, Todd M. Preuss, Xu Chen, and James K. Rilling. 2017. "Evidence for Expansion of the Precuneus in Human Evolution.” Brain Structure and Function 222:1053-1060.

Cacioppo, John T., and Louise C. Hawkley. 2009. "Perceived Social Isolation and Cognition.” Trends in Cognitive Sciences 13(10); 447-454.

Callaway, Ewen. 2014. “Homo erectus made the world's oldest Doodle 500,000 years; Shell markings are the oldest abstract signs every discovered.” Nature News online December 3. [Based on work with a collection by paleontologist Eugène Dubois from Trinil, in Java, in the 1890s.]

Caspers, Julian, Karl Zilles, Katrin Amunts, Angela R. Laird, Peter T. Fox, and Simon B. Eickhoff. 2014. "Functional Characterization and Differential Coactivation Patterns of Two Cytoarchitectonic Visual Areas on the Human Posterior Fusiform Gyrus.” Human Brain Mapping 35(6): 2754-67.

Cavanna, Andrea E., and Michael R. Trimble. 2006. The Precuneus: A Review of Its Functional Anatomy and Behavioural Correlates. Brain 129: 564-583.

Chater, Nick, and Morten H. Christiansen. 2010. “Language Acquisition Meets Language Evolution.” Cognitive Science 34: 1131-1157.

Christiansen, Morten H., and Ralph-Axel Müller. 2014. "Cultural Recycling of Neural Substrates during Language Evolution and Development.” In: The Cognitive Neurosciences V, Michael S. Gazzaniga and George R. Mangun, eds. Cambridge, MA: MIT Press. Pp. 675-682. 
Christiansen, Morten H., Florencia Reali, and Nick Chater. 2011. "Biological Adaptations for Functional Features of Language in the Face of Cultural Evolution.” Human Biology 83: 247259.

Colagè, Ivan. 2015. “The Human Being Shaping and Transcending Itself: Written Language, Brain, and Culture.” Zygon: Journal of Religion and Science 50(4): 1002-1021.

Cole, Steven W. 2013. "Social Regulation of Human Gene Expression: Mechanisms and Implications for Public Health," American Journal of Public Health 103 (S1): S84-S92.

Conway, Christopher C., and George M. Slavich. 2017. "Behavior Genetics of Prosocial Behavior." In: Compassion: Concepts, Research and Application, Paul Gilbert, ed. Ch. 9, pp. 151-169. London: Routledge Publishing.

Coolidge, Frederick. L., and Thomas Wynn. 2009. The Rise of Homo sapiens; The Evolution of Modern Thinking. Chichester, England: Wiley-Blackwell.

D’Ambrosio, Paolo, and Ivan Colagè. 2017. "Extending Epigenesis: From Phenotypic Plasticity to the Bio-Cultural Feedback.” Biology \& Philosophy in press. (Preprint http://philsciarchive.pitt.edu/13196/)

Deane-Drummond, Celia. 2017. "Empathy and the Evolution of Compassion: From Deep History to Infused Virtue.” Zygon: Journal of Religion and Science 52(1): 258-278.

Dehaene, Stanislas, and Leonardo Cohen. (2007). "Cultural Recycling of Cortical Maps.” Neuron 56: 384-398.

Ebstein, Richard P., Ariel Knafo, David Mankuta, Soo Hong Chew, and Poh San Lai. 2012. "The Contributions of Oxytocin and Vasopressin Pathway Genes to Human Behavior." Hormones and Behavior 61(3): 359-79.

Enhanced Strong's Dictionary. (Olive Tree Bible Software: https://www.olivetree.com/ )

Ferguson, Michael A., Jared A. Nielsen, Jace B. King, Li Dai, Danielle M. Giangrasso, Rachel Holman, Julie R. Korenberg, and Jeffrey S. Anderson. 2016. "Reward, Salience, and Attentional Networks are Activated by Religious Experience in Devout Mormons.” Social Neuroscience (Nov.): 1-13. DOI:10.1080/17470919.2016.1257437

Fleagle, John G., Zelalem Assefa, Francis H. Brown, and John J. Shea. 2008.

"Paleoanthropology of the Kibish Formation, Southern Ethiopia: Introduction." Journal of Human Evolution 55(3): 360-365.

Forbes, Chad E., and Jordan Grafman. 2013. "Social Neuroscience: The Second Phase.” Frontiers in Human Neurosciences (Feb.) DOI:10.3389/fnhum.2013.00020 
Gallese, Vittorio. 2008. "Mirror Neurons and the Social Nature of Language: The Neural Exploitation Hypothesis.” Social Neuroscience 3: 317-333.

Gazzaniga, Michael S. 1999. “The Interpreter Within: The Glue of Conscious Experience.” Dana Foundation web site, April 1. http://www.dana.org/Cerebrum/Default.aspx?id=39343\#sthash.I7zCiFeL.dpuf

Gazzaniga, Michael S., and George R. Mangun, Eds. 2014. The Cognitive Neurosciences, Fifth Edition. Cambridge, MA: MIT Press.

Givón, Thomas, and Bertram F. Malle, Eds. 2002. The Evolution of Language Out of PreLanguage. Amsterdam: Benjamins.

Glimcher, Paul. 2014. “The Emerging Standard Model of the Human Decision-Making Apparatus.” In: The Cognitive Neurosciences, Fifth Edition. Michael S. Gazzaniga and George R. Mangun, Eds. Cambridge, MA: MIT Press. Pp. 683-691.

Gnadt, James W. and Richard A. Andersen. 1988. "Memory Related Motor Planning Activity in Posterior Parietal Cortex of Macaque." Experimental Brain Research 70(1): 216-220.

Goetz, Jennifer L., Dacher Keltner, and Emiliana Simon-Thomas. 2010. "Compassion: An Evolutionary Analysis and Empirical Review.” Psychological Bulletin 136(3): 351-374.

Gould, Stephen Jay. 1979. “The Spandrels of San Marco and the Panglossian Paradigm: A Critique of the Adaptationist Programme.” Proceedings of the Royal Society B 205: 581-598.

Gunz, Philipp, Simon Neubauer, Bruno Maureille, and Jean-Jacques Hublin. 2010. "Brain Development After Birth Differs between Neanderthals and Modern Humans. Current Biology 20: R921-R922.

Hare, Brian, Victoria Wobber, and Richard Wrangham. 2012. "The Self-Domestication Hypothesis: Evolution of Bonobo Psychology Is Due to Selection Against Aggression.” Animal Behaviour 83(3): 573-585.

Harper, Douglas. 2017. "Bowel” in Online Etymology Dictionary. http://www.etymonline.com/index.php?term=bowel, accessed August 30, 2017.

Harris, Eugene E. 2015. Ancestors in Our Genome; the New Science of Human Evolution. Oxford: Oxford University Press.

Harris, Marvin. 2001. The Rise of Anthropological Theory: A History of Theories of Culture. Lanham, MD: AltaMira Press.

Hublin, Jean-Jacques, Abdelouahed Ben-Ncer, Shara E. Bailey, Sarah E. Freidline, Simon Neubauer, Matthew M. Skinner, Inga Bergmann, Adeline Le Cabec, Stefano Benazzi, Katerina 
Harvati, and Philipp Gunz. 2017. "New Fossils from Jebel Irhoud, Morocco and the Pan-African Origin of Homo sapiens.” Nature 546: 289-292.

Hurley, Susan L. 2008. “The Shared Circuits Model (SCM): How Control, Mirroring, and Simulation Can Enable Imitation, Deliberation, and Mindreading.” Behavioral and Brain Sciences 31: 1-58.

Jacob, François. 1977. “Evolution and tinkering.” Science 196: 1161-1166.

Joordens, Josephine C. A., Francesco d'Errico, Frank P. Wesselingh, Stephen Munro, John de Vos, Jakob Wallinga, Christina Ankjærgaard, Tony Reimann, Jan R. Wijbrans, Klaudia F. Kuiper, Herman J. Mucher, Hélène Coqueugniot, Vincent Prié, Ineke Joosten, Bertil van Os, Anne S. Schulp, Michel Panuel, Victoria van der Haas, Wim Lustenhouwer, John J. G. Reijmer, and Wil Roebroeks. 2015. "Homo erectus at Trinil on Java used shells for tool production and engraving.” Nature 518: 228-31.

Kittel, Gerhard, Gerhard Friedrich, and Geoffrey W. Bromiley, Eds. 1985. Theological Dictionary of the New Testament: Abridged in One Volume. Grand Rapids, MI:William B. Eerdmans (Olive Tree Bible Software: https://www.olivetree.com/)

Kogan, Aleksandr, Laura R. Saslow, Emily A. Impett, Christopher Oveis, Dacher Keltner, and Sarina Rodrigues Saturn. 2011. "Thin-Slicing Study of the Oxytocin Receptor (OXTR) Gene and the Evaluation and Expression of the Prosocial Disposition.” Proceedings of the National Academy of Sciences 108(48): 19189-19192.

Lachance, Joseph, and Sarah A. Tishkoff. 2013. "Population Genomics of Human Adaptation.” Annual Review of Ecology, Evolution, and Systematics 44: 123-143.

Mack, Michael, Alison Preston, and Bradley Love. 2013. "Decoding the Brain’s Algorithm for Categorization from Its Neural Implementation." Current Biology 23(10): 2023-2027.

MacLean, Evan L. 2016. "Unraveling the Evolution of Uniquely Human Cognition.” Proceedings of the National Academy of Sciences 113(23): 6348-6354.

Matute, Daniel R. 2013. "The Role of Founder Effects on the Evolution of Reproductive Isolation.” Journal of Evolutionary Biology 26: 2299-2311

Miller, Lisa, Ravi Bansal, Priya Wickramaratne, Xuejun Hao, Craig E. Tenke, Myrna M. Weissman, and Bradley S. Peterson. 2014. "Neuroanatomical Correlates of Religiosity and Spirituality; A Study in Adults at High and Low Familial Risk for Depression.” JAMA Psychiatry 71(2): 128-135.

Mithen, Steven. 1996. The Prehistory of the Mind: The Cognitive Origins of Art and Science. London: Thames and Hudson. . 2009. "The Prehistory of the Religious Mind.” In: Theology, Evolution and the Mind. Neil Spurway, ed. Newcastle upon Tyne: Cambridge Scholars Publishing. Pp. 10-30. 
NASB Greek-English Interlinear of the New Testament. (Olive Tree Bible Software: https://www.olivetree.com/)

Neubauer, Simon, Philipp Gunz, and Jean-Jacques Hublin. 2010. “Endocranial Shape Changes During Growth in Chimpanzees and Humans: A Morphometric Analysis of Unique and Shared Aspects.” Journal of Human Evolution 59: 555-566.

Newberg, Andrew B. 2010. Principles of Neurotheology. Farnham, UK: Ashgate Publishing.

Newsome, William T., Kenneth H. Britten, C. Daniel Salzman, and J. Anthony Movshon. 1990. "Neuronal Mechanisms of Motion Perception." Cold Spring Harbor Symposia on Quantitative Biology 55: 697-705.

Nussbaum, Martha. 2014. “Compassion: Human and Animal.” In Understanding Moral Sentiments: Darwinian Perspectives? edited by Hilary Putnam, Susan Neiman, and Jeffrey Schloss. 123-50. London: Transaction Publishers.

Peacock, James L., and A. Thomas Kirsch. 1970. The Human Direction; An Evolutionary Approach to Social and Cultural Anthropology. New York: Appleton-Century-Crofts.

Pyysiäinen, Ilkka, and Marc Hauser. 2010. "The origins of religion: Evolved adaptation or byproduct?” Trends in Cognitive Sciences 14(3): 104-9.

Rappaport, Margaret Boone, and Christopher J. Corbally. 2015. "Matrix Thinking: An Adaptation at the Foundation of Human Science, Religion, and Art.” Zygon; Journal of Religion and Science 50(1): 84-112.

.2016a. "The Human Hearth and the Dawn of Morality.” Zygon: Journal of Religion and Science 51: 835-866. . 2016b. "The Emotional Brain Hypothesis: Emotional, Social, and Religious Vetting in the Evolution of Rational Decision Making and Scientific Modeling." Issues in Science and Theology: Do Emotions Shape the World? Eds. Dirk Evers, Michael Fuller, Anne Runehov, and Knut-Willy Saether. New York: Springer Publishing. Ch. 10, pp. 133-142. . 2017. "Human Phenotypic Morality and the Biological Basis for Knowing Good.” Zygon: Journal of Religion and Science 52: 822-846. . 2018a. "Evolution of Religious Capacity: Origins and Building Blocks." Zygon: Journal of Religion and Science. . 2018b. "Evolution of Religious Capacity in Genus Homo: Cognitive Time Sequence.” Zygon: Journal of Religion and Science. . 2018c. "Evolution of Religious Capacity in Genus Homo: Trait Complexity in Action through Compassion.” Zygon: Journal of Religion and Science.

Robinson, Gene E., Russell D. Fernald, and David F. Clayton. 2008. "Genes and Social Behavior.” Science 322(5903): 896-900. 
Sasaki, Joni Y., Taraneh Mojavereian, and Heejung S. Kim. 2015. "Religion Priming and an Oxytocin Receptor Gene (OXTR) Polymorphism Interact to Affect Self-Control in a Social Context. Development and Psychopathology 27: 97-109.

Schneider, Dana, Virginia P. Slaughter, Stephanie I. Becker, and Paul E. Dux. 2014. “Implicit False-Belief Processing in the Human Brain.” Neuroimage 101: 268-275.

Schrago, Carlos G. 2013. "The Effective Population Sizes of the Anthropoid Ancestors of the Human-Chimpanzee Lineage Provide Insights on the Historical Biogeography of the Great Apes.” Molecular Biology and Evolution 31(1): 37-47. . 2014. "Estimation of the Ancestral Effective Population Sizes of African Great Apes under Different Selection Regimes.” Genetica 142: 273-280.

Soltani, Alireza, and Xiao-Jing Wang. 2008. "From Biophysics to Cognition: Reward-dependent Adaptive Choice Behavior.” Current Opinion in Neurobiology 18(2): 209-216.

Uncapher, Melina R., Alan M. Gordon, and Anthony D. Wagner 2014. "Parietal Lobe Mechanisms Subserving Episodic Memory Retrieval. In: Michael S. Gazzaniga and George R. Mangun, eds., The Cognitive Neurosciences, Fifth edition. Pp. 567-576. Cambridge, MA: MIT Press.

Van Slyke, James A. 2011. The Cognitive Science of Religion. Burlington, VT: Ashgate Publishing.

Varki, Ajit, and Tasha K. Altheide. 2005. "Comparing the Human and Chimpanzee Genomes: Searching for Needles in a Haystack.” Genome Research 15: 1746-1758.

Villmoare, Brian, William H. Kimbel, Chalachew Seyoum, Christopher J. Campisano, Erin N. DiMaggio, John Rowan, David R. Braun, J. Ramón Arrowsmith, and Kaye E. Reed. 2015. “Early Homo at 2.8 Ma from Ledi-Geraru, Afar, Ethiopia.” Science 347(6228): 1352-1355.

Watts, Fraser, and Léon Turner. 2014. Evolution, Religion, and Cognitive Science; Critical and Constructive Essays. Oxford: Oxford University Press.

Whitehouse, Harvey. 2004. Modes of Religiosity: A Cognitive Theory of Religious Transmission. Lanham, MD: AltaMira Press.

Wood, Derek R. W., I. Howard Marshall, Allan R. Millard, James I. Packer, and Donald J. Wiseman (Editors). 1996. New Bible Dictionary 3rd Edition. Downers Grove, IL: Intervarsity Press (version from Olive Tree Bible Software: https://www.olivetree.com/ ).

Wright, Robert. 2001. Nonzero: The Logic of Human Destiny. Reprint edition. New York: Vintage Publishing. 
Zuidema, Willem. 2003. "How the Poverty of the Stimulus Solves the Poverty of the Stimulus." In: S. Becker, S. Thrun, and K. Obermayer, eds. Advances in Neural Information Processing. Pp. 51-58. Cambridge, MA: MIT Press. 